\title{
Aerosol absorption and radiative forcing
}

\author{
P. Stier ${ }^{1, *}$, J. H. Seinfeld ${ }^{1,2}$, S. Kinne ${ }^{3}$, and O. Boucher ${ }^{4}$ \\ ${ }^{1}$ Department of Environmental Science and Engineering, California Institute of Technology, Pasadena, USA \\ ${ }^{2}$ Department of Chemical Engineering, California Institute of Technology, Pasadena, USA \\ ${ }^{3}$ Aerosols, Clouds, and Climate, Max Planck Institute of Meteorology, Hamburg, Germany \\ ${ }^{4}$ Met Office Hadley Centre for Climate Change, Exeter, UK \\ *now at: Atmospheric, Oceanic and Planetary Physics, University of Oxford, UK
}

Received: 26 April 2007 - Published in Atmos. Chem. Phys. Discuss.: 30 May 2007

Revised: 26 July 2007 - Accepted: 20 September 2007 - Published: 10 October 2007

\begin{abstract}
We present a comprehensive examination of aerosol absorption with a focus on evaluating the sensitivity of the global distribution of aerosol absorption to key uncertainties in the process representation. For this purpose we extended the comprehensive aerosol-climate model ECHAM5HAM by effective medium approximations for the calculation of aerosol effective refractive indices, updated black carbon refractive indices, new cloud radiative properties considering the effect of aerosol inclusions, as well as by modules for the calculation of long-wave aerosol radiative properties and instantaneous aerosol forcing. The evaluation of the simulated aerosol absorption optical depth with the AERONET sun-photometer network shows a good agreement in the large scale global patterns. On a regional basis it becomes evident that the update of the $\mathrm{BC}$ refractive indices to Bond and Bergstrom (2006) significantly improves the previous underestimation of the aerosol absorption optical depth. In the global annual-mean, absorption acts to reduce the shortwave anthropogenic aerosol top-of-atmosphere (TOA) radiative forcing clear-sky from -0.79 to $-0.53 \mathrm{~W} \mathrm{~m}^{-2}$ (33\%) and all-sky from -0.47 to $-0.13 \mathrm{~W} \mathrm{~m}^{-2}(72 \%)$. Our results confirm that basic assumptions about the $\mathrm{BC}$ refractive index play a key role for aerosol absorption and radiative forcing. The effect of the usage of more accurate effective medium approximations is comparably small. We demonstrate that the diversity in the AeroCom land-surface albedo fields contributes to the uncertainty in the simulated anthropogenic aerosol radiative forcings: the usage of an upper versus lower bound of the AeroCom land albedos introduces a global annual-mean TOA forcing range of $0.19 \mathrm{~W} \mathrm{~m}^{-2}$ (36\%) clear-sky and of $0.12 \mathrm{~W} \mathrm{~m}^{-2}(92 \%)$ all-sky. The consideration of black carbon inclusions on cloud radiative properties results in a small global annual-mean all-sky absorption of $0.05 \mathrm{~W} \mathrm{~m}^{-2}$ and a positive TOA forcing perturbation
\end{abstract}

Correspondence to: P. Stier

(philip.stier@atm.ox.ac.uk) of $0.02 \mathrm{~W} \mathrm{~m}^{-2}$. The long-wave aerosol radiative effects are small for anthropogenic aerosols but become of relevance for the larger natural dust and sea-salt aerosols.

\section{Introduction}

Atmospheric aerosols play an important role in the global climate system through modifications of the global radiation budget: directly, by scattering and absorption of radiation (e.g. Ångström, 1962; McCormic and Ludwig, 1967; Schulz et al., 2006); indirectly, by the modification of cloud properties and abundance (e.g. Twomey, 1974, 1977; Albrecht, 1989; Lohmann and Feichter, 2005); and semi-directly, by the effect of the direct and indirect aerosol effects on cloud properties and abundance via the modification of the thermal structure of the atmosphere and the surface energy budget (Hansen et al., 1997; Ackerman et al., 2000; Lohmann and Feichter, 2005). Aerosol absorption is of particular importance for both direct and semi-direct aerosol effects; however, the magnitude of aerosol absorption on the global scale and its contribution to global warming is subject to considerable uncertainty (Cooke and Wilson, 1996; Cooke et al., 1999; Hansen et al., 2002; Jacobson, 2002; Menon et al., 2002; Chung and Seinfeld, 2002, 2005; Bond and Sun, 2005; Kinne et al., 2006; Roeckner et al., 2006; Stier et al., 2006b; Schulz et al., 2006).

A number of factors complicate the understanding of aerosol absorption, even at the local scale. The radiative properties of an individual particle are determined by the particle composition and the associated component refractive indices as well as by its size and shape (e.g. Bohren and Huffman, 1998). It follows from Mie theory that, to a first order, aerosol extinction per unit aerosol mass is largest when the aerosol radius is comparable to the wavelength of the radiation (e.g. Bohren and Huffman, 1998). This has important implications for natural and anthropogenic aerosol radiative

Published by Copernicus Publications on behalf of the European Geosciences Union. 
effects. Anthropogenic aerosols are formed predominantly by combustion and gas-to-particle conversion, resulting in average particle sizes at which most of the anthropogenic aerosol mass resides in the sub-micron accumulation mode size-range. By contrast, the predominant sources of natural particles are sea salt and mineral dust, both emitted by wind-driven processes as primary particles with a large contribution in the super-micron coarse mode size ranges (e.g. Seinfeld and Pandis, 2006). Therefore, it can be expected that the long-wave aerosol radiative effects will be of primary importance for the larger natural aerosols.

Black carbon (BC), also referred to as "elemental carbon" or "light absorbing carbon", emitted from incomplete combustion processes, is the dominant absorber of solar radiation under present day conditions, followed by mineral dust (DU) that has typically an imaginary part of the refractive index that is about two orders of magnitude smaller than for BC (e.g. Kinne et al., 2003). While present day BC is predominantly of anthropogenic origin (Ito and Penner, 2005; Stier et al., 2006b), the contribution of anthropogenically disturbed soils to the DU emissions is uncertain (Tegen and Fung, 1995; Mahowald and Luo, 2003; Tegen et al., 2004; Mahowald et al., 2004). The refractive index of representative $\mathrm{BC}$ and DU particles is subject to considerable uncertainty (Bond and Bergstrom, 2006; Balkanski et al., 2007), resulting in diverse assumptions in aerosol models and measurement retrievals.

As $\mathrm{BC}$ is the predominant anthropogenic aerosol absorber, it is a focal point of this study. Observations show that black carbon particles have complex non-spherical morphologies upon emission, depending on the source type and combustion temperature (Mikhailov et al., 2006; Andreae and Gelencsér, 2006) affecting their radiative properties (Martins et al., 1998a; van Poppel et al., 2005). Microphysical ageing processes and subsequent mixing with other aerosol components tend to transform these structures to more spherical morphologies, supporting the spherical approximation and application of Mie theory in large-scale modelling (Martins et al., 1998b; Mikhailov et al., 2006) that will also be used throughout this study.

The radiative properties of an aerosol population depend further on the aerosol mixing state, that is the degree to which the chemical components occur as independent particles (external mixing) as compared to a component mixture in each individual particle (internal mixing). Within the framework of Mie theory, internal mixtures are generally represented by effective medium approximations that quantify the macroscopic radiative properties of the mixture as an average over the microscopic arrangement of the components. Practically this is approached through mixing rules that calculate an effective complex refractive index from the refractive indices of the individual components. A wide range of mixing rules have been developed of which the simple volume-weighted averaging of the component complex refractive indices is most widely used in atmospheric appli- cations. The internal mixing of a population of black carbon with other aerosol components enhances the co-single scattering albedo of the population, and therefore the absorption optical depth, i.e. the column integrated extinction owing to absorption (Ackerman and Toon, 1981; Chýlek et al., 1995; Jacobson, 2000; Stier et al., 2006c). However, in recent work we showed that microphysical ageing processes leading to the internal mixing of initially hydrophobic BC with hydrophilic aerosols, such as sulfate, decrease the atmospheric lifetime and abundance of $\mathrm{BC}$ and compensate for the absorption enhancement by internal mixing (Stier et al., 2006c).

The actual atmospheric aerosol absorption over the atmospheric column with given aerosol radiative properties depends on its global spatio-temporal distribution. In particular, the vertical distribution relative to clouds and the surface albedo play a role, as overlying clouds reduce the incoming solar radiation and the surface albedo and underlying clouds regulate the upwelling solar radiation available for absorption. The simulated or retrieved aerosol absorption depends also on the radiative transfer scheme and its spectral resolution, as well as on the assumptions about aerosol effects within clouds.

Both interstitial aerosols and aerosols embedded in cloud droplets and ice crystals affect cloud radiative properties. It has been estimated that absorption from embedded aerosols could be a non-negligible contributor to short-wave cloud absorption, potentially reaching up to $1-3 \mathrm{~W} \mathrm{~m}^{-2}$ (Chýlek et al., 1996) in the global annual-mean. In their lower estimate Chýlek et al. (1996) have found relatively small global impact, in agreement with other studies (Chuang et al., 2002; Liu et al., 2002); however, as pointed out in Chýlek et al. (1996), the underlying assumptions about the BC abundance in their work and the work of Liu et al. (2002) might not be applicable for highly polluted areas.

The effect of atmospheric absorption on the top-ofatmosphere (TOA) aerosol radiative forcing, i.e. net change in the radiative fluxes at TOA introduced by the aerosols, depends crucially on the effective albedo of the underlying surface (e.g. Haywood and Shine, 1995; Myhre et al., 2003, 2004). The aerosol single scattering albedo (SSA), i.e. the ratio of the extinction due to scattering to the total extinction due to scattering and absorption, decreases with increasing aerosol absorption. For a certain threshold SSA, the critical single scattering albedo (Haywood and Shine, 1995), the combined aerosol-surface system reflects less solar radiation back to space than the surface of a specific surface albedo alone. In this case the SW TOA forcing becomes positive and the aerosols warm the earth system. It is important to note that optically deep clouds under an aerosol layer also serve effectively as a high albedo surface. Thus, absorbing aerosols above a cloud layer have the potential to introduce positive TOA forcings as evident in the spatial distribution of the all-sky forcing estimates in Schulz et al. (2006). 
This complex dependency of aerosol absorption on the aerosol microphysical state, i.e. the composition, size distribution, and mixing state, complicates its simulation in global aerosol models as well as the retrieval from remote sensing instruments.

Early global circulation model based estimates of climatic effects of aerosol absorption focused on specific events such as nuclear winter (Pittock et al., 1986; Turco et al., 1990) or the Kuwait oil fires after 1990 (Bakan et al., 1991). The effects of black carbon on the atmospheric radiation balance and the potential for positive TOA forcing have been conceptually explored by Haywood and Shine (1995). Subsequently, a number of studies investigated the general radiative effects of absorbing carbonaceous aerosols, employing bulk aerosol schemes in global circulation models (Cooke and Wilson, 1996; Liousse et al., 1996; Cooke et al., 1999; Chung and Seinfeld, 2002, 2005). By now, most multicomponent global aerosol models include a bulk representation of the predominant absorbers, black carbon and mineral dust, with prescribed size distributions and assumptions about the aerosol mixing state. A few studies prescribe ageing times from externally-mixed hydrophobic to hydrophilic BC that in some studies is then treated as an internal mixture with sulfate for the radiation calculations. See Textor et al. (2006) for an overview of current aerosol models. A few global aerosol models include a prognostic treatment of the aerosol mixing that allows simulation of variations in the $\mathrm{BC}$ mixing state under different aerosol emission scenarios (Jacobson, 2001; Stier et al., 2005).

There exist a number of studies in which the global distribution of aerosol absorption has been computed, generally as part of an overall analysis of aerosol radiative forcing. As noted, the absorption portion is likely the most uncertain component of direct aerosol radiative forcing. Only few studies evaluate the simulated aerosol absorption. Other studies focus on individual processes relevant for aerosol absorption, such as refractive index mixing rules (e.g. Ackerman and Toon, 1981; Chýlek et al., 1995, 2000; Jacobson, 2000). The objective of the present study is to carry out a comprehensive, measurement constrained examination of aerosol absorption. A focus is on evaluating the sensitivity of the global distribution of aerosol absorption to key uncertainties in the process representation. These include aerosol absorbing component refractive indices, surface albedo, refractive indices mixing rules, and the absorption of aerosol inclusions in cloud droplets and ice crystals. Predictions of present day aerosol absorption optical depths and the sensitivity to the process representations are evaluated and quantified with observations from the global AERONET sun-photometer network (http://aeronet.gsfc.nasa.gov; Holben et al., 1998; Dubovik and King, 2000; Holben et al., 2001). Another key uncertainty in model based estimates of aerosol absorption are the emissions of carbonaceous aerosols that have been discussed in much detail (Cooke et al., 1996; Liousse et al., 1996; Cooke, 1997; Cooke et al., 1999; van der Werf et al.,
2003; Bond et al., 2004; Schaap et al., 2004; Rao et al., 2005; Ito and Penner, 2005) and will not be considered in this study.

To facilitate this investigation we further extend and evaluate the comprehensive aerosol climate model ECHAM5HAM (Stier et al., 2005), concentrating on the representation of aerosol absorption. The ECHAM5-HAM model is described in Sect. 2 with a brief summary of the base configuration as in Stier et al. (2005) in Sect. 2.1 and its extension for this study in Sect. 2.2. The base and sensitivity simulations are described in Sect. 3. Results and discussion are presented in Sect. 4 followed by conclusions in Sect. 5 .

\section{Model description}

In this study we employ the aerosol-climate model ECHAM5-HAM with a prognostic representation of the composition, size distribution, and mixing state of the major global aerosol components: sulfate, black carbon, particulate organic matter, sea salt, and mineral dust (Stier et al., 2005). A brief description of ECHAM5-HAM, employed in its version echam_5.3.01_ham_1.51, is presented in the first part of this section. More details and an extensive evaluation of this base model can be found in Stier et al. (2005). The extensions of the representation of aerosol absorption in ECHAM5-HAM are given in the second part of the section.

\subsection{ECHAM5-HAM}

\subsubsection{The atmospheric general circulation model ECHAM5}

The atmospheric general circulation model (GCM) ECHAM5 (Roeckner et al., 2003) is the fifth-generation climate model developed at the Max Planck Institute for Meteorology. ECHAM5 solves prognostic equations for vorticity, divergence, surface pressure, and temperature, expressed in terms of spherical harmonics with a triangular truncation. Non linear processes and the physical parameterisations are solved on a corresponding Gaussian grid. Water vapour, cloud liquid water, cloud ice, and trace components are transported in grid-point space with a flux form semi-Lagrangian transport scheme (Lin and Rood, 1996). ECHAM5 contains a bulk microphysical stratiform cloud scheme (Lohmann and Roeckner, 1996) with prognostic equations for cloud liquid water and ice. Cloud cover is predicted with a prognostic-statistical scheme solving equations for the distribution moments of total water (Tompkins, 2002). Convective clouds and convective transport are based on the mass-flux scheme of Tiedtke (1989) with modifications by Nordeng (1994), based on steady-state equations for mass, heat, moisture, cloud water, and momentum for an ensemble of updrafts and downdrafts. Cloud water detrainment from convective updrafts is used as source term in the stratiform cloud water equations. The short-wave radiation scheme of Fouquart and Bonnel (1980) 
Table 1. Modal structure of the aerosol module HAM where SU (sulfate), BC (black carbon), POM (particulate organic matter), SS (sea salt), DU (mineral dust) denote the components in the respective modes.

\begin{tabular}{lll}
\hline Modes & Hydrophilic & Hydrophobic \\
\hline Nucleation & SU & \\
Aitken & SU, BC, POM & BC, POM \\
Accumulation & SU, BC, POM, SS, DU & DU \\
Coarse & SU, BC, POM, SS, DU & DU \\
\hline
\end{tabular}

is employed with 4 spectral bands, one for the visible and ultra-violet, and three for the near-infrared. It uses the Eddington approximation for the integration over the zenith and azimuth angles and the delta-Eddington approximation for the reflectivity of a layer. The long-wave radiation scheme (Mlawer et al., 1997; Morcrette et al., 1998) has 16 spectral bands.

\subsubsection{The aerosol module HAM}

The microphysical aerosol module HAM (Stier et al., 2005) predicts the evolution of an ensemble of seven interacting internally- and externally-mixed log-normal aerosol modes. In the current setup, the components comprise: sulfate, black carbon, particulate organic matter, sea salt, and mineral dust. The aerosol mixing state is prognosed within the possible mixing state configurations illustrated in Table 1. The modes are composed either of hydrophobic compounds or of an internal mixture of hydrophobic and hydrophilic compounds, henceforth denoted as hydrophilic modes. The main components of HAM are the microphysical core M7, a sulfur chemistry scheme, a module to calculate the aerosol radiative properties, a deposition module, and an emission module.

The microphysical core M7 (Vignati et al., 2004) calculates the coagulation of aerosol particles, condensation of gas-phase sulfuric acid on the aerosol surface, binary nucleation of sulfate, and water uptake.

The sulfur cycle model (Feichter et al., 1996) treats the prognostic variables dimethyl sulfide (DMS), sulfur dioxide, sulfate and their gas- and aqueous-phase reaction pathways, using pre-calculated monthly mean oxidant fields.

Aerosol radiative properties, as well as the sink processes dry deposition, sedimentation, and wet deposition, are parameterised in dependence on the prognostic aerosol size distribution, composition, and mixing state and coupled to the ECHAM5 meteorology.

Aerosol radiative properties are calculated in the framework of Mie theory. For each aerosol mode, effective refractive indices are calculated by volume-averaging the refractive indices of all components, including aerosol water, which is parameterised in terms of ambient relative humidity. The effective complex refractive indices and the Mie size-
Table 2. Global annual aerosol and aerosol-precursor emissions used in the simulations in $\mathrm{Tg} \mathrm{yr}^{-1}$ and $\operatorname{Tg}(\mathrm{S}) \mathrm{yr}^{-1}$ for sulfur species. The range for the sea salt and mineral dust emissions indicate small fluctuations of the interactive sources.

\begin{tabular}{|c|c|c|c|}
\hline Species & Source & Year 1750 & Year 2000 \\
\hline \multirow[t]{2}{*}{ DMS } & Marine Biosphere & 23.5 & 23.5 \\
\hline & Terrestrial Biosphere & 0.3 & 0.3 \\
\hline \multirow[t]{3}{*}{$\mathrm{SO}_{2}$} & Volcanoes & 14.6 & 14.6 \\
\hline & Vegetation Fires & 0.7 & 2.1 \\
\hline & $\begin{array}{l}\text { Industry, Fossil-Fuel, } \\
\text { Bio-Fuels }\end{array}$ & 0.8 & 54.2 \\
\hline Total sulfur & & 39.9 & 94.6 \\
\hline \multirow[t]{3}{*}{$\mathrm{BC}$} & Vegetation Fires & 1.0 & 3.0 \\
\hline & Fossil-Fuel & 0.0 & 3.0 \\
\hline & Bio-Fuels & 0.4 & 1.6 \\
\hline Total BC & & 1.4 & 7.7 \\
\hline \multirow[t]{4}{*}{ POM } & Biogenic & 19.1 & 19.1 \\
\hline & Vegetation Fires & 12.7 & 34.7 \\
\hline & Fossil-Fuel & 0.0 & 3.4 \\
\hline & Bio-Fuels & 2.0 & 9.1 \\
\hline Total POM & & 33.8 & 66.3 \\
\hline SS & Wind driven & $5050 \pm 5$ & $5050 \pm 5$ \\
\hline DU & Wind driven & $820 \pm 10$ & $820 \pm 10$ \\
\hline
\end{tabular}

parameters for each mode serve as input to look-up tables for the aerosol radiative properties, providing extinction crosssection, single scattering albedo, and asymmetry parameter to the ECHAM5 radiation scheme. To allow the investigation of a wide range of refractive indices we extended the upper boundary of the range of the imaginary part of the refractive index in the look-up tables from $0.5 i$ to $1.0 i$ for this study.

Aerosol wet deposition is parameterised in terms of the aerosol size distribution and mixing state via modespecific scavenging ratios, specifying embedded and interstitial aerosol fractions in the cloudy part of a grid box and in convective updrafts. The actual wet deposition is calculated from the resulting embedded aerosol content based on the precipitation formation and re-evaporation calculated by the ECHAM5 cloud scheme. Aerosol and gas dry deposition velocities are calculated based on a serial resistance approach (Stier et al., 2005; Ganzeveld et al., 2006).

Emissions of mineral dust are calculated online depending on the ECHAM5 10-m wind speed, soil moisture, and snow cover (Tegen et al., 2002, 2004). Freshly emitted BC and mineral dust are assumed hydrophobic. Sea salt emissions are parameterised in terms of the simulated 10-m wind speed and sea-ice cover (Schulz et al., 2004). Emissions of DMS are calculated interactively from DMS seawater concentrations of Kettle and Andreae (2000) depending on the 
simulated 10-m wind speed and sea surface temperature, applying the sea-air exchange formulation of Nightingale et al. (2000). Terrestrial biogenic DMS emissions are prescribed (Pham et al., 1995). For all other compounds, emission strength, distribution, and height are based on the AeroCom aerosol model inter-comparison (http://nansen.ipsl.jussieu. fr/AEROCOM/) emission inventory representative for the years 2000 and 1750 (Dentener et al., 2006). The emissions for the years 1750 and 2000 are summarised in Table 2.

\subsection{Extensions of ECHAM5-HAM}

\subsubsection{Mixing rules for refractive indices}

The prognostic treatment of the aerosol mixing state requires the interactive computation of the aerosol radiative properties from the composition of each mode. In standard HAM, the effective refractive index of each mode is obtained by volume-weighted averaging of the refractive index of its components. However, as discussed in Chýlek et al. (1995) and Lesins et al. (2002), the volume-weighted mixing of the refractive indices for strongly absorbing inclusions, such as $\mathrm{BC}$, in a less absorbing medium, such as sulfate, results in an overestimate of the effective imaginary part of the refractive index as compared to an average of explicit calculations over all possible positions of an inclusion in the host medium. A more accurate approximation for effective refractive indices can be obtained from mixing rules derived from effective medium approaches, quantifying the macroscopic radiative properties as an average over the microscopic arrangement of the components.

A general formulation for mixing rules of $n$ components can be expressed as (Aspnes, 1982):

$$
\frac{\epsilon_{\text {eff }}-\epsilon_{0}}{\epsilon_{\text {eff }}+2 \epsilon_{0}}=\sum_{k=1}^{n} f_{k} \frac{\epsilon_{k}-\epsilon_{0}}{\epsilon_{k}+2 \epsilon_{0}}
$$

where $\epsilon_{\text {eff }}$ is the complex effective dielectric constant of the mixture, $\epsilon_{0}$ is the complex dielectric constant of the host medium, and $\epsilon_{k}$ and $f_{k}$ are the complex dielectric constant and volume fraction of component $k$, respectively.

The appropriate mixing rule for the inclusion of an insoluble core in a liquid host medium is the Maxwell-Garnet mixing rule (Garnett, 1904, 1906), see Chýlek et al. (2000) and Lesins et al. (2002). However, it requires the explicit choice of a host and an inclusion medium. As the volume fractions of the components in the internally-mixed aerosol modes of HAM are highly variable and the modes can be composed of mixtures of either dry or solid components, the application of the Maxwell-Garnett mixing rule is not straightforward. The mixing rule of Bruggeman (1935), best suited for internal mixtures of solid compounds (see Chýlek et al., 2000; Lesins et al., 2002), does not require the explicit definition of host and inclusion media. The resulting real and imaginary parts of the refractive indices obtained from the Bruggeman mixing rule lie in-between the results of the two possible choices of host and inclusion media in the Maxwell-Garnet mixing rule (Chýlek et al., 2000).

In the Maxwell-Garnet mixing rule one of the mode components $(k=1)$ is chosen as the host medium, i.e. $\epsilon_{1}=\epsilon_{0}$, so that the first term of the sum in Eq. (1) vanishes and the system reduces to:

$$
\frac{\epsilon_{\mathrm{eff}}-\epsilon_{1}}{\epsilon_{\mathrm{eff}}+2 \epsilon_{1}}=\sum_{k=2}^{n} f_{k} \frac{\epsilon_{k}-\epsilon_{1}}{\epsilon_{k}+2 \epsilon_{1}}
$$

so that

$\epsilon_{\text {eff }}=\epsilon_{1} \frac{1+2 \sum_{k=2}^{n} f_{k} \frac{\epsilon_{k}-\epsilon_{1}}{\epsilon_{k}+2 \epsilon_{1}}}{1-\sum_{k=2}^{n} f_{k} \frac{\epsilon_{k}-\epsilon_{1}}{\epsilon_{k}+2 \epsilon_{1}}}$

For the Bruggeman mixing rule no choice of a host medium is required as it is assumed that the components are embedded in a host medium of the effective dielectric constant, i.e. $\epsilon_{0}=\epsilon_{\text {eff }}$, so that the left-hand side in Eq. (1) vanishes and the system is reduced to the implicit equation for $\epsilon_{\mathrm{eff}}$ :

$$
f\left(\epsilon_{\mathrm{eff}}\right)=\sum_{k=1}^{n} f_{k} \frac{\epsilon_{k}-\epsilon_{\mathrm{eff}}}{\epsilon_{k}+2 \epsilon_{\mathrm{eff}}}=0
$$

2.2.2 Calculation of effective aerosol refractive indices employing the Bruggeman mixing rule

As the component volume fractions for the modes of ECHAM5-HAM are highly variable, we employ in this study the Bruggeman mixing rule as an alternative method for the calculation of the mode effective complex refractive indices $\left(n_{\text {eff }}=\sqrt{\epsilon_{\text {eff }}}\right)$ in ECHAM5-HAM. (The MaxwellGarnet mixing rule has also been implemented but requires somewhat arbitrary choices of host and inclusion media.) Using

$f^{\prime}\left(\epsilon_{\mathrm{eff}}\right)=\sum_{k=1}^{n} f_{k} \frac{-3 \epsilon_{k}}{\left(\epsilon_{k}+2 \epsilon_{\mathrm{eff}}\right)^{2}}$

we solve Eq. (4) with a Newton iteration over the index $v$ :

$\epsilon_{\mathrm{eff}}^{\nu+1}=\epsilon_{\mathrm{eff}}^{\nu}-\frac{f\left(\epsilon_{\mathrm{eff}}^{\nu}\right)}{f^{\prime}\left(\epsilon_{\mathrm{eff}}^{\nu}\right)}$

The number of required iterations for convergence was determined not to exceed six iterations at any grid point in a one-year test simulation, so that a fixed number of seven iterations is applied globally.

2.2.3 Parameterisation of the effect of aerosol inclusions on cloud radiative properties employing the MaxwellGarnett mixing rule

To facilitate the investigation of aerosol inclusions on the cloud radiative properties, we recompute the standard ECHAM5 cloud radiative properties (Roeckner et al., 2003; Rockel et al., 1991) including aerosol effects. Analogous to 
Table 3. Size-distribution parameters $r_{\text {eff }}[\mu \mathrm{m}]$ and $v_{\text {eff }}$ of the 32 water droplet and 40 ice crystal distributions (Rockel et al., 1991).

\begin{tabular}{lll}
\hline Water & $r_{\text {eff }}$ & $0.188,0.375,0.75,1.5,3,6,12,24$ \\
& $v_{\text {eff }}$ & $0.01,0.1,0.175,0.25$ \\
\hline Ice & $r_{\text {eff }}$ & $0.375,0.75,1.5,3,6,12,24,40,60,80$ \\
& $v_{\text {eff }}$ & $0.001,0.1,0.175,0.25$ \\
\hline
\end{tabular}

the parameterisation of the aerosol radiative properties, we tabulate the cloud radiative properties in a look-up table as a function of the effective refractive index of the cloud droplets with aerosol inclusions.

In standard ECHAM5, short-wave cloud radiative properties are parametrised from idealised size-distributions (Rockel et al., 1991) under the assumption of spherical cloud droplets and ice crystals. From a series of Mie calculations, fits are derived to express the resulting radiative properties of cloud droplets and ice crystals in terms of the effective radius (Roeckner et al., 2003) that is empirically related to the radius of average volume by Johnson (1993) for water droplets and by Moss (personal communication as in Roeckner et al., 2003) for ice crystals.

For the extended parameterisation we repeated the Mie calculations of the cloud radiative properties for varying cloud droplet or ice crystal refractive indices. For each complex pair of the refractive indices, we use Mie calculations (Toon and Ackerman, 1981) to compute, as in ECHAM5, radiative properties for cloud droplets and ice crystals as an average over idealised gamma size-distributions following Hansen and Travis (1974):

$n(r)=C r^{\frac{1-3 v_{\mathrm{eff}}}{v_{\mathrm{eff}}}} e^{\frac{-r}{r_{\mathrm{eff}} v_{\mathrm{eff}}}}$

where $C$ is a constant and $v_{\text {eff }}$ is the effective variance of the distribution, with the specifications given in Table 3 based on Rockel et al. (1991).

The computed radiative properties for cloud droplet and ice crystal extinction cross section, single scattering albedo, and asymmetry factor are provided in a look-up table with three dimensions: Mie effective size-parameter $\left(X_{\text {eff }}=2 \pi r_{\text {eff }} / \lambda\right)$, as well as real and imaginary parts $\left(n_{r}\right.$ and $n_{i}$ ) of the effective refractive index of the cloud water - aerosol mixture.

The standard ECHAM5 cloud droplet concentration $N_{l}$ is prescribed within the boundary layer as $220 \times 10^{6} \mathrm{~m}^{-3}$ over land and as $80 \times 10^{6} \mathrm{~m}^{-3}$ over sea. Above the boundary layer, $N_{l}$ decreases exponentially to $50 \mathrm{~m}^{-3}$ in the upper troposphere over both land and ocean. The cloud ice crystal number concentration is calculated from the ice water mixing ratio via an empirical parameterisation of the effective radius (Moss, 1996, personal communication as in Roeckner et al., 2003). In an extended version of ECHAM5-HAM, the standard bulk stratiform cloud scheme of ECHAM5 (Lohmann and Roeckner, 1996) has been replaced by a microphysical cloud parameterisation with a prognostic treatment of the cloud droplet number concentration and ice crystal number concentration (Lohmann et al., 2007).

Contrary to standard ECHAM5-HAM, in which all aerosol within the cloudy fraction of a grid box is assumed interstitial with identical radiative properties as for clear-sky, the in-cloud aerosol content is split into interstitial aerosol and cloud droplet/crystal inclusions that are considered for the cloud radiative properties. For the calculation of the cloud droplet and ice crystal effective refractive indices, the aerosol content associated with water droplet/ice crystal inclusions is calculated consistently from the prescribed ECHAM5-HAM scavenging ratios (Stier et al., 2005), defined as the fraction of aerosol embedded in cloud droplets or ice crystals within the cloudy fraction of a grid box. The embedded aerosol content is assumed uniformly distributed over all cloud droplets and ice crystals. The volume fraction of the aerosol inclusions can be considered small for cloud droplets and ice crystals so that the Maxwell-Garnett mixing rule (Eq. 3) is employed for the calculation of the effective dielectric constants, from which the complex refractive index is derived by taking the complex root $n_{\text {eff }}=\sqrt{\epsilon_{\text {eff }}}$. For the case of pure water clouds, as applied in the CL-INT sensitivity study (see Sect. 3), the aerosol volume fractions in Eq. (3) are zero and the effective refractive index reduces to the host medium value. While all aerosol components could be considered for the calculation of the cloud droplet/crystal refractive indices via Eq. (3), here we activate only the effect of $\mathrm{BC}$ on the cloud radiative properties, as the orders of magnitude larger BC imaginary part of the refractive index will dominate the total aerosol effect.

\subsubsection{Long-wave aerosol radiative properties}

The radiation module of ECHAM5-HAM has been extended to also cover the long-wave radiative properties of aerosol, in analogy to the original short-wave radiation module (Stier et al., 2005). The long-wave aerosol radiative properties are pre-computed from Mie theory for the 16 long-wave spectral bands of the Mlawer et al. (1997); Morcrette et al. (1998) radiation scheme of ECHAM5 and supplied in look-up tables with the three dimensions: Mie median size-parameter $\left(X_{g}=2 \pi r_{g} / \lambda\right)$, and real and imaginary parts of the refractive index. Hereby, $r$ is the number median radius of the log-normal mode and $\lambda$ is the wavelength. Effective refractive indices of internally-mixed modes are calculated by volume-weighted averaging of the component refractive indices (default) or by the Bruggeman mixing rule as described in Sect. 2.2.1. References for the implemented long-wave refractive indices are given in Table 4, and the spectral dependence of the refractive indices is depicted in Fig. 1. 


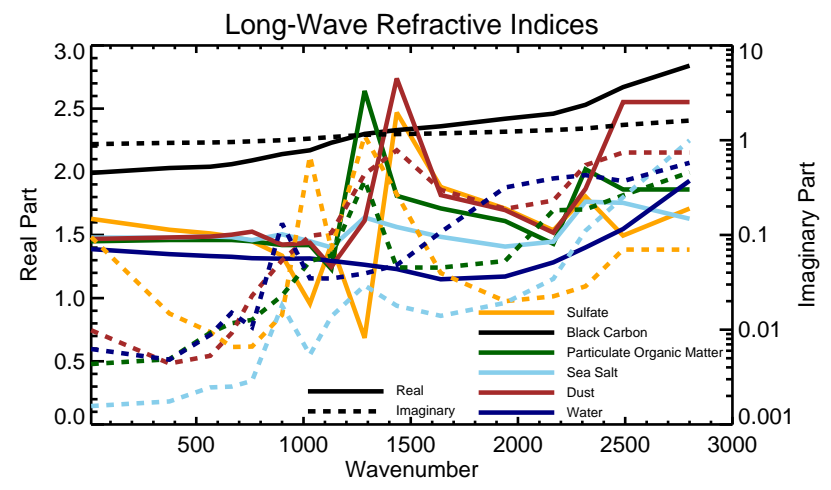

Fig. 1. Long-wave component refractive indices as given in Table 4.

Table 4. References for the long-wave aerosol refractive indices shown in Fig. 1.

\begin{tabular}{ll}
\hline Species & Reference \\
\hline SU & Toon et al. (1976) \\
BC & $\begin{array}{l}\text { Bond and Bergstrom (2006) } \\
\text { spectrally extrapolated with Hess et al. (1998) }\end{array}$ \\
POM & Hess et al. (1998) \\
SS & Shettle and Fenn (1979); Nilsson (1979) \\
DU & Irina Sokolik (pers. comm., 2006) \\
WAT & Downing and Williams (1975) \\
\hline
\end{tabular}

\subsubsection{Instantaneous forcing calculation}

We have extended ECHAM5-HAM by a module for the calculation of instantaneous direct aerosol radiative forcing (as already applied in Schulz et al., 2006). Due to the internal mixing of mode components and the resulting nonlinear effects of individual components on the aerosol microphysical state and radiative properties (Stier et al., 2006c), it is not possible to directly calculate radiative forcing for individual components. Instead, we calculate total aerosol radiative forcing by a double call of the ECHAM5 radiation scheme, without and with the radiative properties of the total aerosols. The instantaneous direct aerosol radiative forcing is then computed as the difference in the separate clear-sky and all-sky, short-wave and long-wave net radiative fluxes, without and with aerosols. No adjustment of stratospheric temperatures is performed in the forcing calculations.

\section{Simulation setup}

To investigate aerosol absorption and its radiative effects we perform a series of sensitivity studies with the ECHAM5HAM model in which we vary key uncertainties in model parameterisations and compare the results to observations as well as the Stier et al. (2005) base simulation.
Table 5. Studies to explore the sensitivity of the simulated absorption to uncertain model parameters. Each scenario is simulated with AeroCom year 2000 and 1750 emissions.

\begin{tabular}{|c|c|}
\hline Name & Description \\
\hline BASE & Base run as in Stier et al. (2005) \\
\hline BB-M & $\begin{array}{l}\text { Updated medium absorbing refractive indices } \\
\text { from Bond and Bergstrom (2006) }\end{array}$ \\
\hline BB-H & $\begin{array}{l}\text { Updated highly absorbing refractive indices } \\
\text { from Bond and Bergstrom (2006) }\end{array}$ \\
\hline BRUG & $\begin{array}{l}\text { As BB-M but with Bruggeman (1935) } \\
\text { mixing rule for refractive indices }\end{array}$ \\
\hline ALB-L & $\begin{array}{l}\text { As BB-M but with low AeroCom } \\
\text { surface albedo estimate }\end{array}$ \\
\hline ALB-H & $\begin{array}{l}\text { As BB-M but with high AeroCom } \\
\text { surface albedo estimate }\end{array}$ \\
\hline TRANS & $\begin{array}{l}\text { As BB-M but with imaginary part of all aerosol } \\
\text { refractive indices set to } n_{i}=10^{-9}\end{array}$ \\
\hline CL-INC & $\begin{array}{l}\text { As BB-M but with new cloud radiative properties } \\
\text { and in-cloud aerosol split in interstitial and cloud } \\
\text { droplet/crystal inclusions that are considered via } \\
\text { cloud radiative properties }\end{array}$ \\
\hline CL-INT & $\begin{array}{l}\text { As CL-INC with new cloud radiative properties and } \\
\text { interstitial aerosol but without consideration } \\
\text { of cloud droplet/crystal inclusions via cloud radiative } \\
\text { properties }\end{array}$ \\
\hline CL-EXT & $\begin{array}{l}\text { As CL-INC with new cloud radiative properties but } \\
\text { all in-cloud aerosol considered as interstitial, } \\
\text { i.e. externally mixed with cloud droplets }\end{array}$ \\
\hline
\end{tabular}

For each simulation we run ECHAM5-HAM from October 1999 to December 2000 and constrain the large-scale meteorology to the year 2000 by nudging (Jeuken et al., 1996) the model to the ECMWF ERA40 reanalysis data (Simmons and Gibson, 2000). Only the year 2000 data are analysed. We employ a horizontal resolution of T63 in spectral space with a corresponding resolution of $1.8^{\circ} \times 1.8^{\circ}$ on a Gaussian grid. The vertical resolution is set to 31 levels, extending from the surface up to $10 \mathrm{hPa}$. Aerosol and aerosol precursor emissions are identical in all simulations, except for small variations in the interactive sources owing to small variations in the local scale meteorology. To isolate the effect of anthropogenic emissions, each study is performed twice with emissions from the AeroCom emission inventory (Dentener et al., 2006) representative for the years 2000 and 1750. An overview of the simulations performed is given in Table 5 .

The first series of simulations (BASE, BB-M, BB-H) is aimed at exploring the sensitivity of the aerosol absorption and radiative forcing to uncertainties in the $\mathrm{BC}$ refractive indices. The BASE simulation is physically identical to that of Stier et al. (2005), however, has been performed with an updated model version, as described in Sect. 2. In the BB-M and $\mathrm{BB}-\mathrm{H}$ simulations we employ the medium and highly absorbing $\mathrm{BC}$ refractive indices from Bond and Bergstrom (2006), respectively, as given in Table 6. As Bond and 
Table 6. Complex BC refractive indices at $\lambda=550 \mathrm{~nm}$ used in the sensitivity studies.

\begin{tabular}{lll}
\hline Name & Refractive Index & Reference \\
\hline BASE & $1.75+0.44 i$ & Hess et al. (1998) \\
BB-M & $1.85+0.71 i$ & Bond and Bergstrom (2006) \\
BB-H & $1.95+0.79 i$ & Bond and Bergstrom (2006) \\
TRANS & $1.85+10^{-9} i$ & Sensitivity study \\
\hline
\end{tabular}

Bergstrom (2006) report the $\mathrm{BC}$ refractive indices only at a wavelength of $550 \mathrm{~nm}$, we use the same spectral dependence as in BASE (Hess et al., 1998) to spectrally extrapolate BC refractive indices for $\mathrm{BB}-\mathrm{M}$ and $\mathrm{BB}-\mathrm{H}$.

Variations in the aerosol absorption have been attributed partly to the calculation of the effective refractive indices for internally mixed aerosols, in particular for internal mixtures of BC (Chýlek et al., 1995; Lesins et al., 2002; Jacobson, 2000). To quantify the effect of mixing rules on global atmospheric absorption and radiative forcing we replace in the BRUG simulation the most commonly applied volumeweighted averaging applied in all other simulations with the more elaborate Bruggeman (1935) mixing rule.

Variations in the TOA forcing of absorbing aerosols are often partly attributed to differences in the assumed surface albedos (e.g. Schulz et al., 2006). To quantify this effect, we derive upper and lower estimates of the global surface albedo distribution, as applied in current global aerosol models, and apply those fields in ECHAM5-HAM. We derive these upper and lower bounds from the surface albedo fields submitted by the GISS (Koch et al., 2006), ECHAM5-HAM (Stier et al., 2005), LOA (Reddy et al., 2005), LSCE (see Textor et al., 2006), UIO-GCM (Kirkevåg and Iversen, 2002; Kirkevåg et al., 2005; Iversen and Seland, 2002, 2003), UMI (Liu et al., 2005), and SPRINTARS ${ }^{1}$ (Takemura et al., 2005) global aerosol models to the AeroCom forcing experiment (Schulz et al., 2006). At each grid point of ECHAM5-HAM we select the highest and lowest value of the surface albedo provided by any of the AeroCom models. The resulting upper and lower bounds of the AeroCom surface albedo distributions are depicted in Fig. 2. Please note that the protocol of the AeroCom forcing experiment specified albedo broadly as "surface solar broadband albedo $(0.2-4.0 \mu \mathrm{m})$ ". Therefore, some of the submissions provide the prescribed background surface albedo while others provide the applied effective surface albedo, including the contributions from interactively

\footnotetext{
${ }^{1}$ For SPRINTARS, the AeroCom database contained the visible instead of the broad-band short-wave surface albedo. This field was used in the calculation of the upper and lower bound of the broadband surface albedos. However, a reanalysis of the derived upper and lower bounds without SPRINTARS resulted in almost indistinguishable lower and upper bounds with global annual means of 0.19 and 0.35 , respectively. Therefore, we decided not to repeat the sensitivity studies with the corrected fields.
}
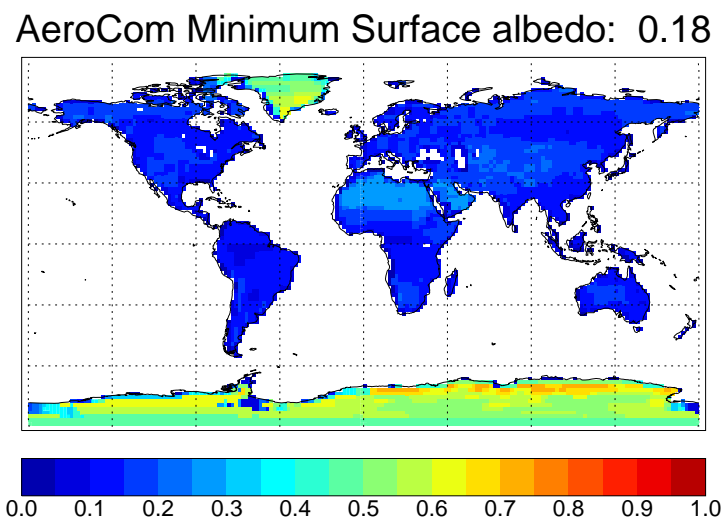

AeroCom Maximum Surface albedo: 0.36

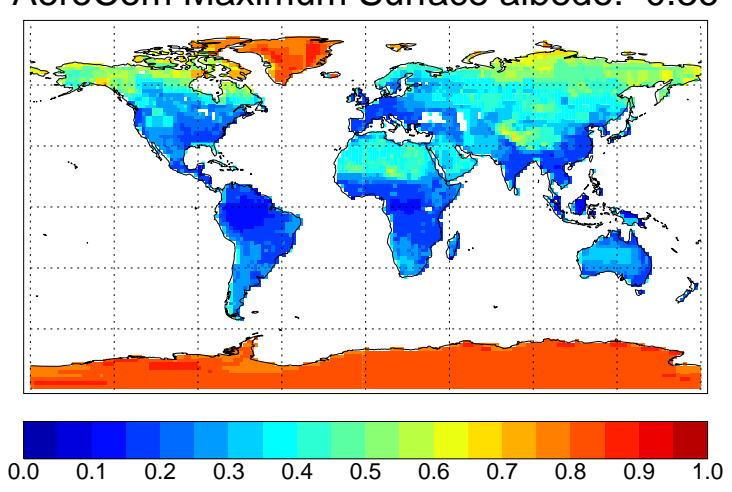

Fig. 2. Global distribution and mean of the upper and lower bound of broadband short-wave $(0.2-4.0 \mu \mathrm{m})$ land surface albedo fields sampled from submissions the AeroCom forcing experiment.

computed snow and ice covers. This might cause a high bias of the upper bound of the surface albedo estimate at high latitudes. For the sensitivity studies with ECHAM5-HAM, we use the the derived lower (ALB-L) and upper (ALB-H) bounds to replace the prescribed background ECHAM5 land surface albedo (Hagemann, 2002) used in all other simulations. The background albedo is modified during the simulation based on the simulated snow cover. We do not modify the original sea and lake surface albedo of ECHAM5, which is set to a constant value of 0.07 (Roeckner et al., 2003).

To quantify the contribution of aerosol absorption to aerosol radiative forcing, we perform a study with transparent aerosols (TRANS), i.e. with the imaginary parts of all aerosol refractive indices set to $n_{i}=10^{-9}$.

The effect of aerosol inclusions on short-wave cloud absorption and the resulting radiative effects are investigated in the CL-INC, CL-INT, and CL-EXT simulations. All employ the new cloud radiative properties described in Sect. 2.2.3. CL-INC is set up as BB-M but with in-cloud aerosol split in interstitial aerosol and cloud droplet/crystal inclusions that are considered in the calculation of the cloud radiative properties via the Maxwell-Garnett mixing rule. CL-INT is iden- 
tical to CL-INC but considers only the interstitial aerosol and not the effect of cloud droplet/crystal inclusions on the new cloud radiative properties. In CL-EXT, all in-cloud aerosol is considered interstitial, i.e. externally mixed with the cloud droplets.

\section{Results}

In this section we will systematically evaluate the sensitivity of aerosol absorption and radiative forcing to key uncertainties in aerosol modelling.

The general setup of our simulations is identical to that in Stier et al. (2005), and the sensitivity studies performed differ only in the representation of the aerosol and surface radiative properties, so that the extensive evaluation of ECHAM5HAM in Stier et al. (2005) does also apply for this study. As the present study focuses on the representation of aerosol absorption, the changes in all simulations affect only minimally the global aerosol optical depth as compared to Stier et al. (2005), with a global annual mean value of 0.14 .

\subsection{Total aerosol absorption and its evaluation}

The simulated global distribution of clear-sky total aerosol absorption optical depth $(\mathrm{AAOD}=\mathrm{AOD}(1-\mathrm{SSA}))$, its seasonal evaluation with AERONET sun-photometer measurements, and the simulated clear-sky total aerosol absorption for the BASE, BB-M, BB-H, and BRUG scenarios are depicted in Figs. 3-6, respectively. For the AAOD evaluation at each AERONET site, the simulated daily mean AAOD values at the model grid-box containing the site have been sampled at the available measurement dates. To minimise the error of the AERONET retrieval, we apply the following procedure for the derivation of daily mean AAOD values from Version 1 Level 2.0 data. We stratify the retrieved aerosol single scattering albedo data for each day into a 5 bin histogram ordered by AOD. If the average AOD is larger than a critical threshold value of 0.3 we adopt the associated single scattering albedo average for the calculation of AAOD. If the average AOD falls below the critical threshold, we adopt the SSA value associated to the first AOD bin average above the threshold. In case the average of even the largest AOD bin stays below the critical threshold, we prescribe the SSA of the largest AOD bin to all bins with lower AOD. This procedure is designed to minimise the potential SSA error for small AODs (small signal to noise ratios).

For the BB-M sensitivity study, all included dailymean AAODs are additionally given as seasonally colourcoded scatterplots for each AERONET site in Appendix A, Fig. A1. The same plots for the BASE, BB-H, and BRUG study can be found in the supplementary online material (http://www.atmos-chem-phys.net/7/5237/ 2007/acp-7-5237-2007-supplement.pdf), SOM-Figs. 1-3.
Aerosol radiative properties and forcings for all simulations are given in Table 7.

The global distribution of the AAOD and aerosol absorption shows maxima in the biomass burning regions of Central Africa and South America, in the Saharan dust plume, and in the regions with high anthropogenic activities over India and South East Asia, as well as secondary maxima over the Eastern U.S. and Central to Eastern Europe. For all simulations, the AERONET evaluation of AAOD shows generally a good agreement in these large-scale global patterns. Also the seasonality is well captured at many AERONET sites, such as the July to September onset of the Southern Hemispheric biomass burning season in South America and Africa.

On a regional basis, general and seasonal biases as well as differences among the simulations become more clearly evident. For example, AAODs at the urban Mexico City site $(99.2 \mathrm{~W}, 19.3 \mathrm{~N})$ as well as over the central European site Lille $(3.1 \mathrm{E}, 50.6 \mathrm{~N})$ are generally underestimated, and the AAOD increase during the Asian spring dust-season at the Mongolian Dalanzadgad site (104.4 E, 43.6 N) is not captured. The BASE simulation has a tendency to generally underestimate AAOD, in particular over the European and US source regions. The increase of the imaginary part of the $\mathrm{BC}$ refractive index from BASE to BB-M and BB-H (Table 6), generally improves the agreement with the AERONET retrieved AAOD. The incomparability of different stations and the consideration of a highly variable number of measurements at each site (Fig. A1) do not seem to allow deriving a global measure of the overall model performance. However, from comparison of Figs. 3-6 and SOM-Figs. 1-3 we conclude that the BB-M (and the very similar BRUG) case seems to provide the best representation of the AERONET retrieved AAOD. Thus, the BB-M simulation will be used as a reference for comparison with the other sensitivity studies.

\subsection{Anthropogenic aerosol absorption and radiative forcing}

\subsubsection{BASE case}

The simulated short-wave anthropogenic aerosol absorption and TOA radiative forcings are depicted in Fig. 7; corresponding global annual-mean total and anthropogenic aerosol radiative properties and forcings are given in Table 7.

For the BASE case, as submitted to the AeroCom forcing experiment (Schulz et al., 2006), the global annual mean short-wave clear- and all-sky anthropogenic aerosol absorption are $0.81 \mathrm{~W} \mathrm{~m}^{-2}$ and $0.74 \mathrm{~W} \mathrm{~m}^{-2}$, these are $46 \%$ and $45 \%$ of the total year 2000 aerosol absorption, respectively. Aerosol absorption generally reduces the amount of solar radiation reflected back to space. Over high surface albedo areas the combined aerosol-surface system reflects less solar radiation back to space than the high albedo surface alone, resulting in a positive TOA forcing and a warming effect. This can be observed in the clear-sky TOA aerosol radiative forcing over North Africa and West Australia. In the all-sky 
Table 7. ECHAM5-HAM simulated short- and long-wave aerosol radiative properties and forcings for the different sensitivity studies. Aerosol optical depths are given at wavelength $\lambda=550 \mathrm{~nm}$. Please note that the BB-M study, showing good agreement with the AERONET AAOD retrieval, serves as reference for comparison with the other studies.

\begin{tabular}{|c|c|c|c|c|c|c|c|c|c|c|}
\hline Study & $\begin{array}{l}\text { AAOD } \\
\text { fClear-Sky } \\
\text { Total } \\
{\left[10^{-3}\right]}\end{array}$ & $\begin{array}{l}\text { AAOD } \\
\text { Clear-Sky } \\
\text { Antrop. } \\
{\left[10^{-3}\right]}\end{array}$ & $\begin{array}{l}\text { Absorption } \\
\text { Clear-Sky } \\
\text { Total } \\
{\left[\mathrm{W} \mathrm{m}^{-2}\right]}\end{array}$ & $\begin{array}{l}\text { Absorption } \\
\text { All-Sky } \\
\text { Total } \\
{\left[\mathrm{W} \mathrm{m}^{-2}\right]}\end{array}$ & $\begin{array}{l}\text { Absorption } \\
\text { Clear-Sky } \\
\text { Anthrop. } \\
{\left[\mathrm{W} \mathrm{m}^{-2}\right]}\end{array}$ & $\begin{array}{l}\text { Absorption } \\
\text { All-Sky } \\
\text { Anthrop. } \\
{\left[\mathrm{W} \mathrm{m}^{-2}\right]}\end{array}$ & $\begin{array}{l}\text { Forcing TOA } \\
\text { Clear-Sky } \\
\text { Total Aerosol } \\
{\left[\mathrm{W} \mathrm{m}^{-2}\right]}\end{array}$ & $\begin{array}{l}\text { Forcing TOA } \\
\text { All-Sky } \\
\text { Total Aerosol } \\
{\left[\mathrm{W} \mathrm{m}^{-2}\right]}\end{array}$ & $\begin{array}{l}\text { Forcing TOA } \\
\text { Clear-Sky } \\
\text { Anthrop. } \\
{\left[\mathrm{W} \mathrm{m}^{-2}\right]}\end{array}$ & $\begin{array}{l}\text { Forcing TOA } \\
\text { All-Sky } \\
\text { Anthrop. } \\
{\left[\mathrm{W} \mathrm{m}^{-2}\right]}\end{array}$ \\
\hline \multicolumn{11}{|l|}{ SW } \\
\hline BASE & 2.1 & 1.3 & 1.78 & 1.63 & 0.81 & 0.74 & -4.02 & -2.51 & -0.65 & -0.27 \\
\hline BB-M & 3.0 & 2.0 & 2.35 & 2.15 & 1.20 & 1.11 & -3.84 & -2.30 & -0.53 & -0.13 \\
\hline BB-H & 3.2 & 2.2 & 2.50 & 2.30 & 1.31 & 1.21 & -3.80 & -2.24 & -0.50 & -0.09 \\
\hline BRUG & 2.6 & 1.7 & 2.12 & 1.95 & 1.05 & 0.97 & -3.90 & -2.37 & -0.58 & -0.18 \\
\hline ALB-L & 3.1 & 2.0 & 2.42 & 2.22 & 1.18 & 1.08 & -4.29 & -2.62 & -0.61 & -0.18 \\
\hline ALB-H & 3.0 & 2.0 & 2.38 & 2.18 & 1.24 & 1.14 & -3.55 & -2.09 & -0.42 & -0.06 \\
\hline TRANS & 0.0 & 0.0 & 0.08 & 0.11 & 0.01 & 0.02 & -3.96 & -2.47 & -0.79 & -0.47 \\
\hline \multicolumn{11}{|l|}{ LW } \\
\hline BASE & & & 1.33 & 0.72 & 0.06 & 0.03 & 0.37 & 0.21 & 0.03 & 0.02 \\
\hline
\end{tabular}

case, clouds below absorbing aerosols serve as an effective high albedo surface so that large regions over South America and regions with persistent fields of stratocumulus clouds of the west coast of Southern Africa show positive TOA aerosol radiative forcings. The global annual-mean short-wave clearsky and all-sky anthropogenic TOA aerosol radiative forcings are $-0.65 \mathrm{~W} \mathrm{~m}^{-2}$ and $-0.27 \mathrm{~W} \mathrm{~m}^{-2}$, respectively.

\subsubsection{Sensitivity to BC refractive indices}

To investigate the sensitivity of aerosol absorption and radiative forcing to the $\mathrm{BC}$ refractive index we increase the imaginary part of the $\mathrm{BC}$ refractive index from 0.44 in BASE to the medium and high recommendations by Bond and Bergstrom (2006) of 0.71 in BB-M and 0.79 in BB-H (at $\lambda=550 \mathrm{~nm}$ ). As evident in Fig. 7, these changes increase the anthropogenic short-wave aerosol absorption from 0.81 to 1.20 and $1.31 \mathrm{~W} \mathrm{~m}^{-2}$ in the clear-sky and from 0.74 to 1.11 and $1.21 \mathrm{~W} \mathrm{~m}^{-2}$ in the all-sky case, respectively. It is interesting to note that while this increase of absorption reduces the TOA forcing from -0.65 to $-0.53(-19 \%)$ and $-0.50 \mathrm{~W} \mathrm{~m}^{-2}$ $(-23 \%)$ for the clear-sky case, the all-sky forcing decreases from -0.27 to $-0.13(-52 \%)$ and $-0.09 \mathrm{~W} \mathrm{~m}^{-2}(-67 \%)$. This highlights the strong sensitivity of the all-sky TOA aerosol radiative forcing to aerosol absorption and the crucial role of the relative location of absorbing aerosols and clouds. For the BB-M study, which shows the best agreement of AAOD with the AERONET sunphotometer network, the TOA aerosol radiative forcing becomes positive over large regions of Africa, South America, Asia and Australia.

\subsubsection{Sensitivity to refractive index mixing rules}

In the BRUG study, we replace the simple volume-weighted averaging calculation of the effective refractive indices for internally mixed modes in BB-M by the Bruggeman (1935) mixing rule. As shown in Table 7, this change decreases the total aerosol clear-sky and all-sky absorption from 2.35 to $2.12 \mathrm{~W} \mathrm{~m}^{-2}(-10 \%)$ and from 2.15 to $1.95 \mathrm{~W} \mathrm{~m}^{-2}$ (-9\%), respectively. This relatively small change of the aerosol absorption, as compared to the change associated with the variations of the $\mathrm{BC}$ refractive indices from BASE to BB-H, does not allow one to identify significant improvements in the evaluation of AAOD with the AERONET sun-photometer network between BB-M (Fig. 4) and BRUG (Fig. 6). The anthropogenic aerosol clear-sky and all-sky TOA radiative forcings intensify from BB-M to BRUG from -0.53 to $-0.58 \mathrm{~W} \mathrm{~m}^{-2}(+9 \%)$ and from -0.13 to $-0.18 \mathrm{~W} \mathrm{~m}^{-2}$ (+39\%), respectively.

\subsubsection{Sensitivity to surface albedo}

The large gradients in the TOA forcing at discontinuities of the surface albedo fields, such as the coasts of Africa, readily suggest a strong dependence of aerosol radiative forcing on the surface albedo. To quantify the effect of common assumptions for the surface albedo on the aerosol absorption and radiative forcing, we replace the land surface albedo field applied in BB-M by the upper (ALB-H) and lower (ALB-L) bound of the reported surface albedos in the AeroCom forcing experiment, as described in Sect. 3. The resulting annualmean difference in the broad-band land surface albedo between the simulations ALB-H and ALB-L is shown in Fig. 8. It is clearly evident that significant surface albedo difference exist between the two simulations, reaching values of 0.5 . Interestingly, the differences are not limited to high latitude areas where different assumptions in snow covers and albedos could play a role in the AeroCom upper bound of the surface albedo. Instead, differences of up to about 0.4 occur over all continents with the largest absolute differences over the high albedo desert areas. The global annual-mean difference is 0.04 and the difference averaged over the land areas is 0.13 . 
Aerosol Absorption Optical Depth: $2.1 \times 10^{-3}$
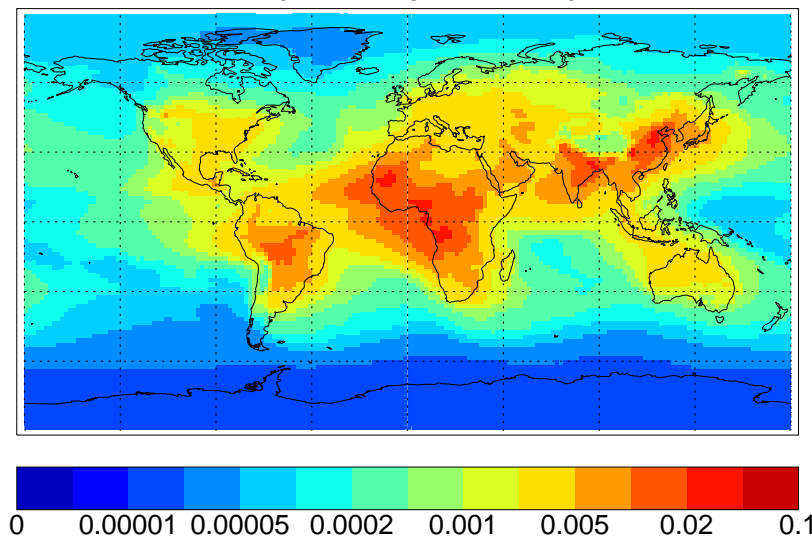

Aerosol Absorption Optical Depth

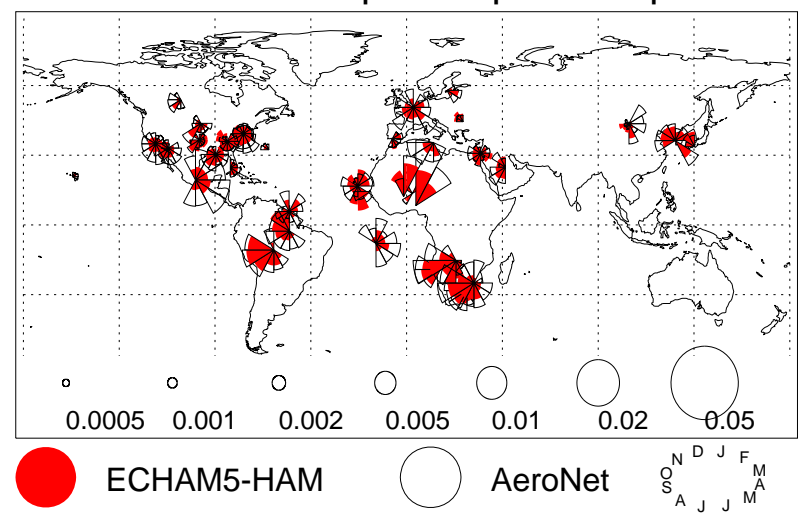

Aerosol Absorption Clear-Sky: $1.78 \mathrm{~W} \mathrm{~m}^{-2}$
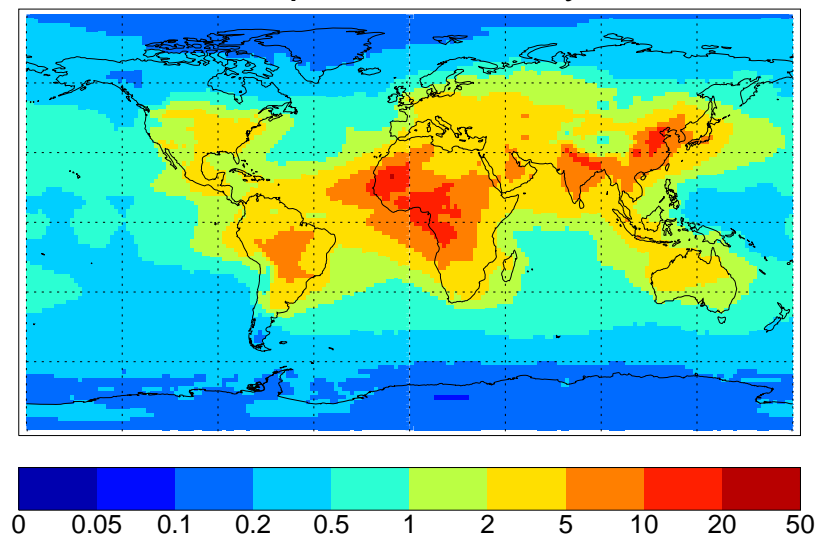

Fig. 3. ECHAM5-HAM simulated BASE year 2000 mean clearsky aerosol absorption optical depth [1] at wavelength $\lambda=550 \mathrm{~nm}$, comparison of simulated (red) and AERONET sun-photometer retrieved (black) clear-sky aerosol absorption optical depth [1] as seasonal distribution (clockwise, starting at 12 o'clock) at respective AERONET locations, simulated clear-sky short-wave aerosol absorption $\left[\mathrm{W} \mathrm{m}^{-2}\right]$. Global annual-mean values are given in the titles.

\section{Aerosol Absorption Optical Depth: 3.0 $10^{-3}$}
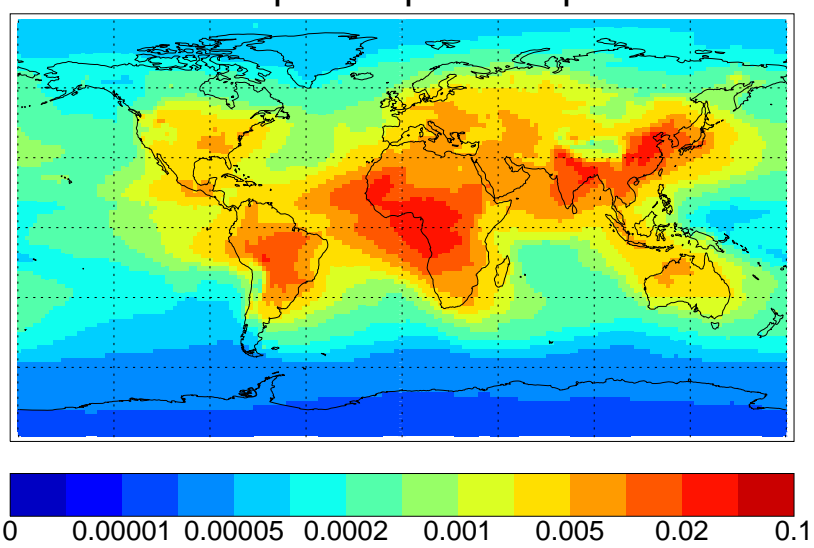

Aerosol Absorption Optical Depth

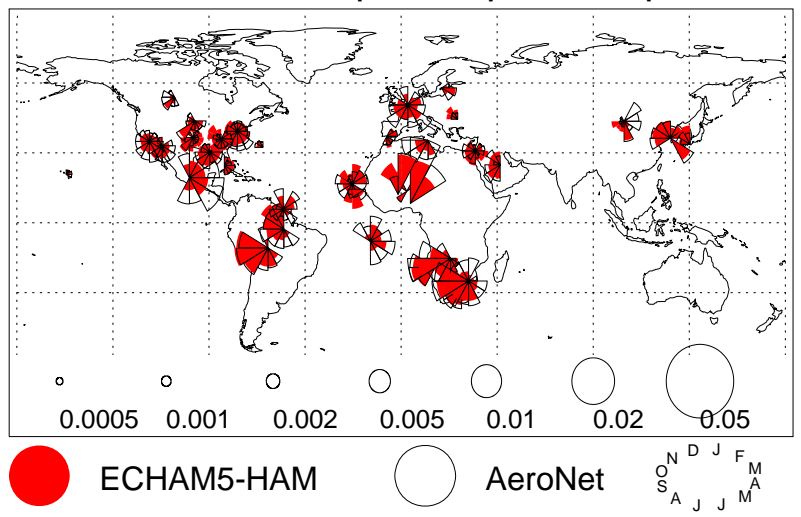

Aerosol Absorption Clear-Sky: $2.35 \mathrm{~W} \mathrm{~m}^{-2}$

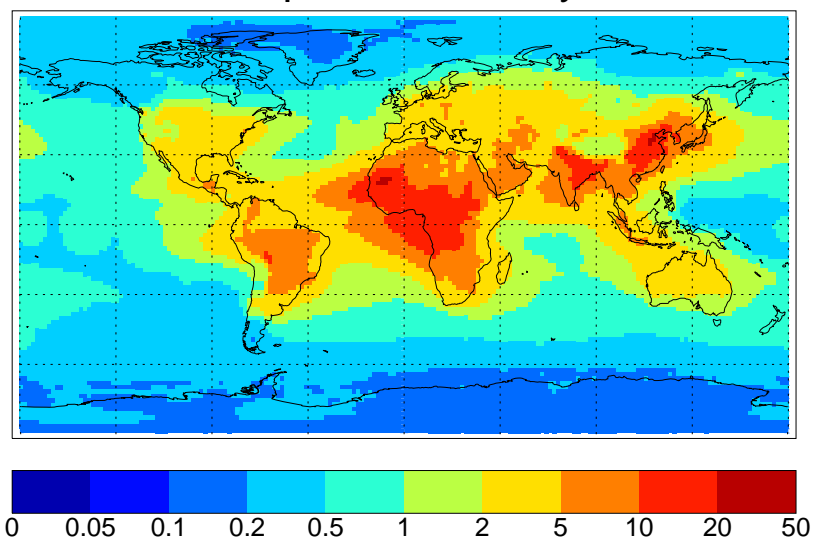

Fig. 4. ECHAM5-HAM simulated BB-M year 2000 mean clearsky aerosol absorption optical depth [1] at wavelength $\lambda=550 \mathrm{~nm}$, comparison of simulated (red) and AERONET sun-photometer retrieved (black) clear-sky aerosol absorption optical depth [1] as seasonal distribution (clockwise, starting at 12 o-clock) at respective AERONET locations, simulated clear-sky short-wave aerosol absorption $\left[\mathrm{W} \mathrm{m}^{-2}\right]$. Global annual-mean values are given in the titles. 


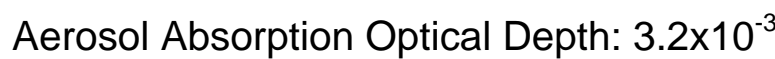
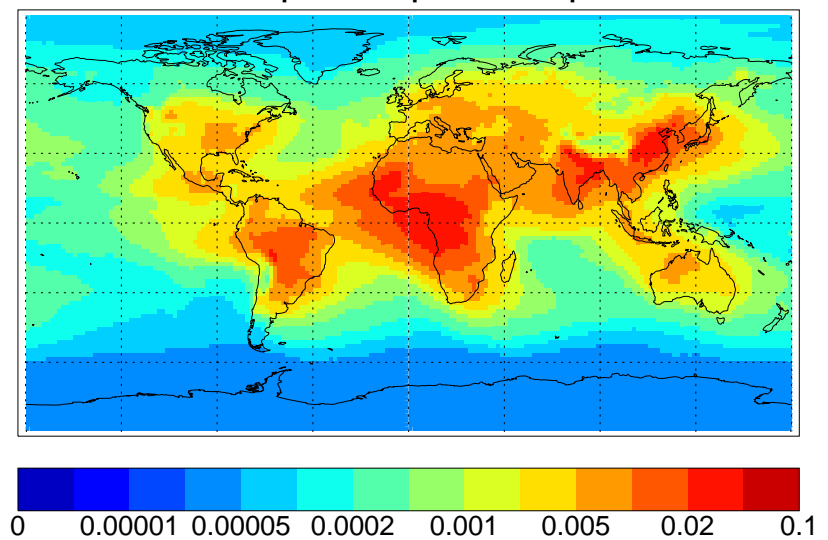

Aerosol Absorption Optical Depth

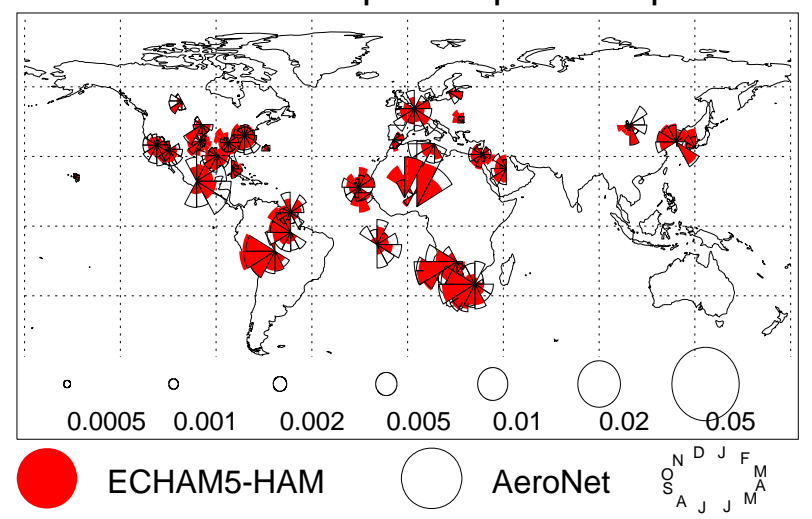

\section{Aerosol Absorption Clear-Sky: $2.50 \mathrm{~W} \mathrm{~m}^{-2}$}
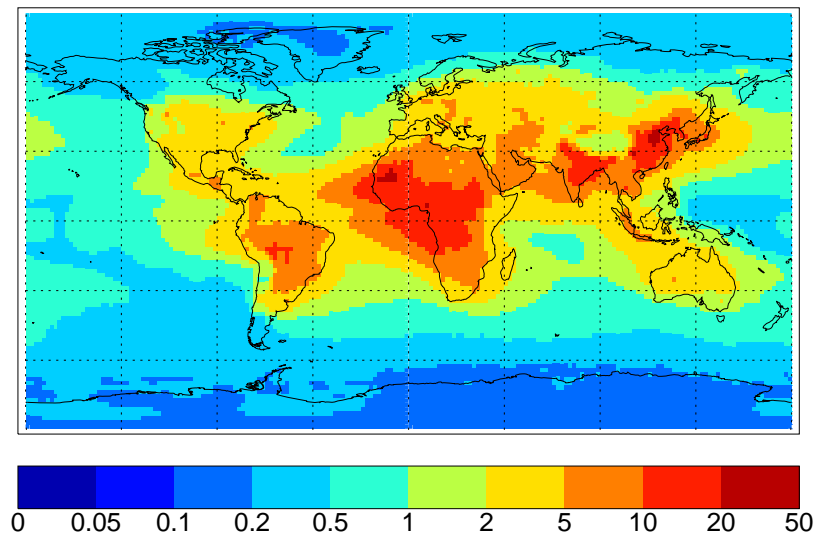

Fig. 5. ECHAM5-HAM simulated BB-H year 2000 mean clearsky aerosol absorption optical depth [1] at wavelength $\lambda=550 \mathrm{~nm}$, comparison of simulated (red) and AERONET sun-photometer retrieved (black) clear-sky aerosol absorption optical depth [1] as seasonal distribution (clockwise, starting at 12 o-clock) at respective AERONET locations, simulated clear-sky short-wave aerosol absorption $\left[\mathrm{W} \mathrm{m}^{-2}\right]$. Global annual-mean values are given in the titles.

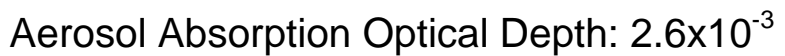
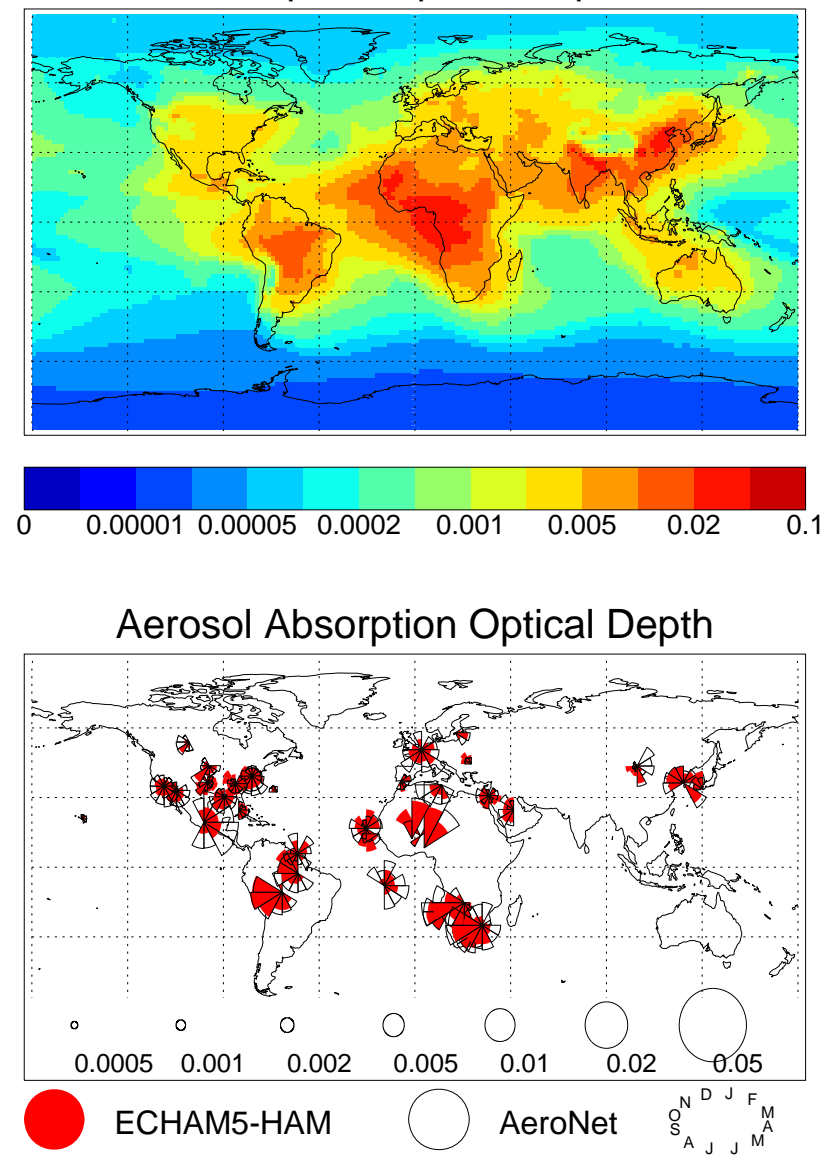

\section{Aerosol Absorption Clear-Sky: $2.12 \mathrm{~W} \mathrm{~m}^{-2}$}
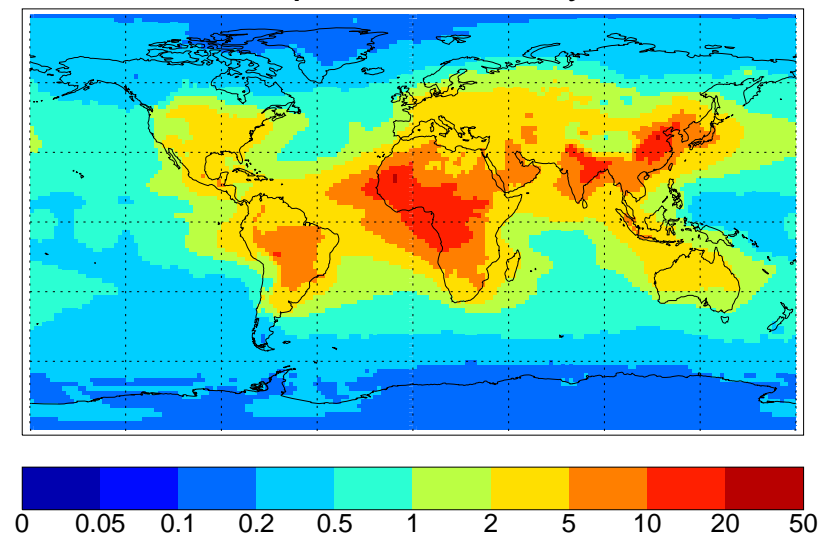

Fig. 6. ECHAM5-HAM simulated BRUG year 2000 mean clearsky aerosol absorption optical depth [1] at wavelength $\lambda=550 \mathrm{~nm}$, comparison of simulated (red) and AERONET sun-photometer retrieved (black) clear-sky aerosol absorption optical depth [1] as seasonal distribution (clockwise, starting at 12 o-clock) at respective AERONET locations, simulated clear-sky short-wave aerosol absorption $\left[\mathrm{W} \mathrm{m}^{-2}\right]$. Global annual-mean values are given in the titles. 

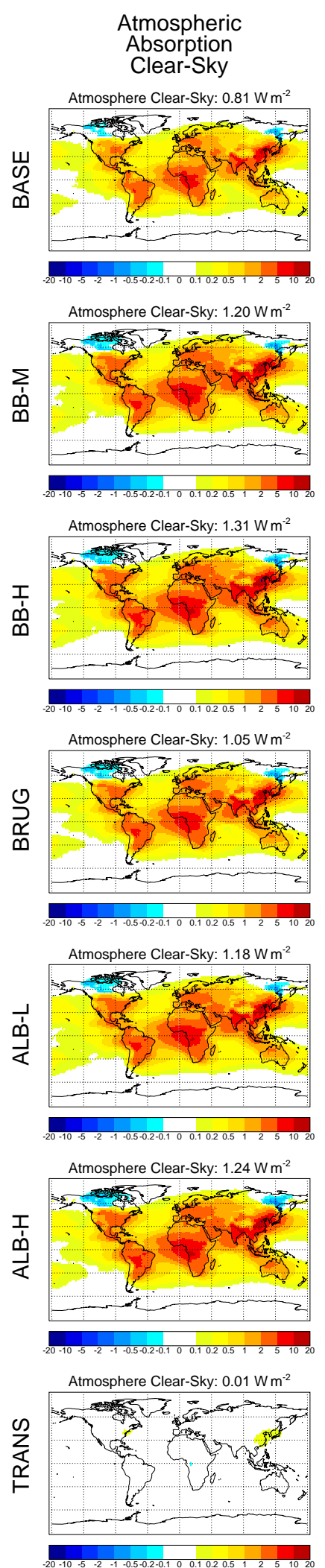
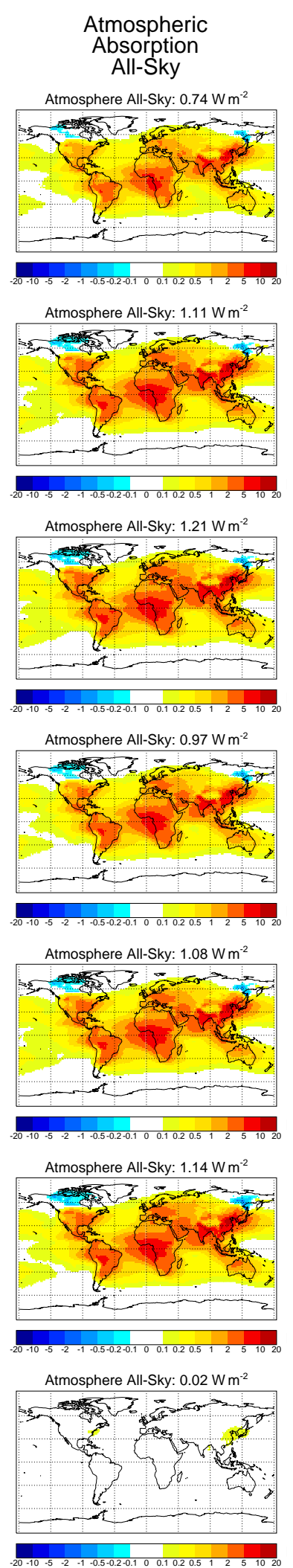

Top-Of-Atmosphere
Forcing

Clear-Sky

TOA Clear-Sky: $-0.65 \mathrm{Wm}^{-2}$
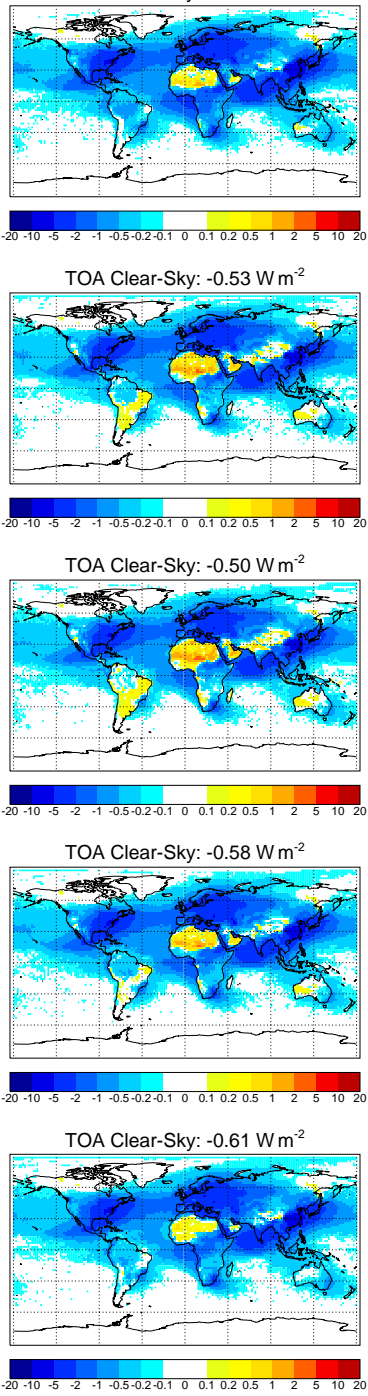

TOA Clear-Sky: $-0.42 \mathrm{Wm}^{-2}$
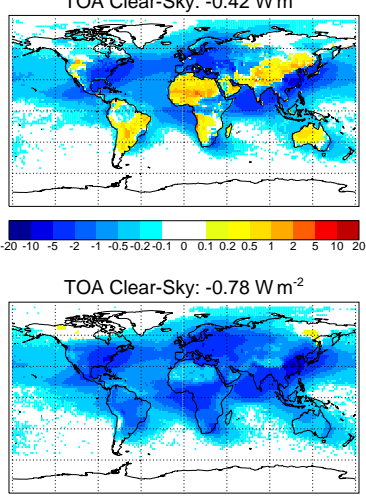

\section{Top-Of-Atmosphere \\ Forcing \\ All-Sky}
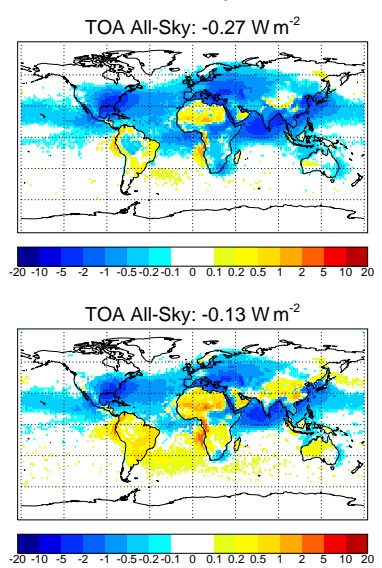

TOA All-Sky: $-0.09 \mathrm{~W} \mathrm{~m}^{-2}$

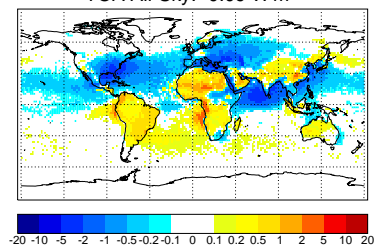

TOA All-Sky: $-0.18 \mathrm{~W} \mathrm{~m}^{-2}$

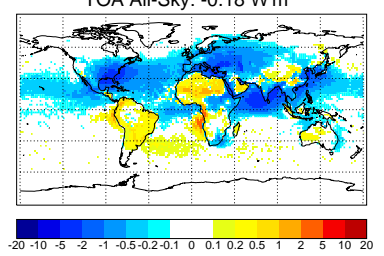

TOA All-Sky: $-0.18 \mathrm{~W} \mathrm{~m}^{-2}$

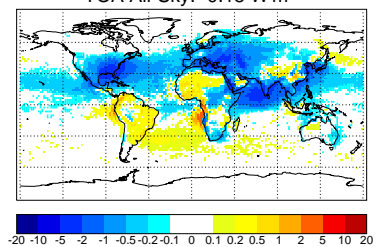

TOA All-Sky: $-0.06 \mathrm{~W} \mathrm{~m}^{-2}$
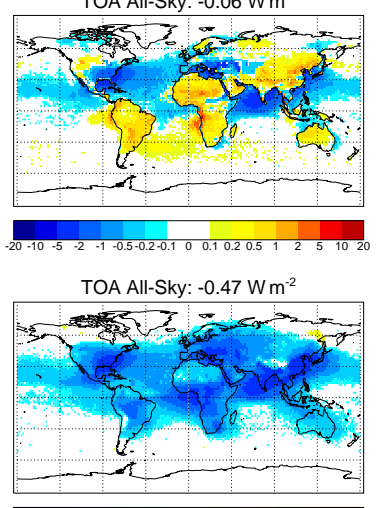

Fig. 7. Simulated year 2000 anthropogenic aerosol short-wave clear-sky atmospheric absorption, all-sky atmospheric absorption, clear-sky TOA forcing, and all-sky TOA forcing $\left[\mathrm{W} \mathrm{m}^{-2}\right]$ for the BASE, BB-M, BB-H, BRUG, ALB-L, ALB-H, and TRANS scenarios. Global annual-mean values are given in the titles. 


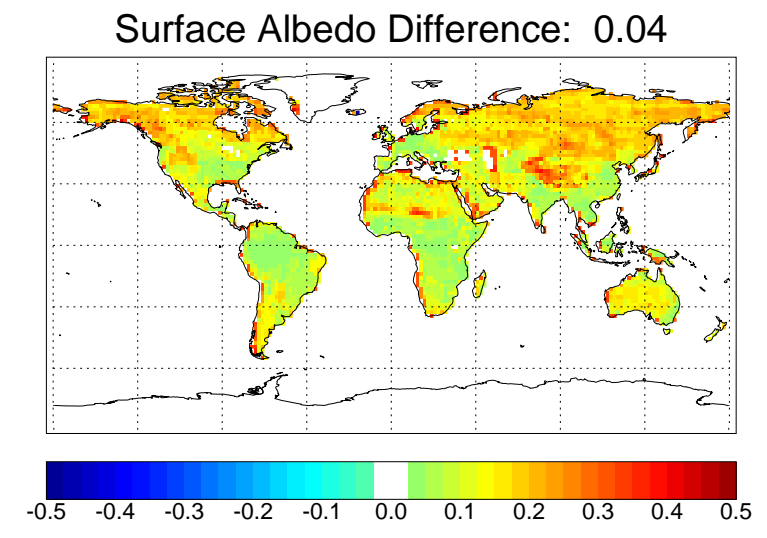

Fig. 8. Annual-mean difference in the effective ECHAM5-HAM broad-band surface albedo between the simulations with the the upper (ALB-H) and lower (ALB-L) bound of the AeroCom land surface albedos. The global annual mean value in the title includes unchanged ocean areas to allow for a comparison with the global forcings in Fig. 9

The resulting modification of the upwelling surface shortwave radiative fluxes cause small changes in the clearand all-sky anthropogenic aerosol absorption of less than $0.05 \mathrm{~W} \mathrm{~m}^{-2}$ (Table 7). However, the corresponding anthropogenic TOA aerosol radiative forcing changes from -0.53 in BB-M to $-0.61(+15 \%)$ in ALB-L and $-0.42 \mathrm{~W} \mathrm{~m}^{-2}$ $(-21 \%)$ in ALB-H for the clear-sky case and the all-sky forcing change from -0.13 in BB-M to $-0.18(+39 \%)$ in ALB-L and $-0.06 \mathrm{~W} \mathrm{~m}^{-2}(-54, \%)$ in ALB-H (Table 7 and Fig. 7). The difference of clear-sky and all-sky anthropogenic direct aerosol radiative forcings between the ALB-H and ALB-L simulations is shown in Fig. 9. Over large regions, such as East Asia, the differences of the clear-sky TOA anthropogenic forcing due to the use of different surface albedo datasets reach up to $2-5 \mathrm{~W} \mathrm{~m}^{-2}$, locally up to $10 \mathrm{~W} \mathrm{~m}^{-2}$. The global annual-mean difference in the anthropogenic TOA aerosol radiative forcing between the cases with the upper and the lower bounds of the AeroCom land-surface albedo is $0.20 \mathrm{~W} \mathrm{~m}^{-2}$ (clear-sky) and $0.12 \mathrm{~W} \mathrm{~m}^{-2}$ (all-sky), respectively.

\subsection{Contribution of aerosol absorption to radiative forcing}

The difference between the BB-M and TRANS simulations allows one to isolate the effect of aerosol absorption on radiative forcing. Unlike studies with absorbing aerosols omitted, this method does not alter the aerosol microphysical state by changing the number of emitted primary particles that can act as seeds for secondary particle growth (Stier et al., 2006a; Pierce and Adams, 2007).

The comparison of the global patterns of short-wave anthropogenic aerosol radiative forcing in Fig. 7 shows the very similar distribution of negative aerosol radiative per-
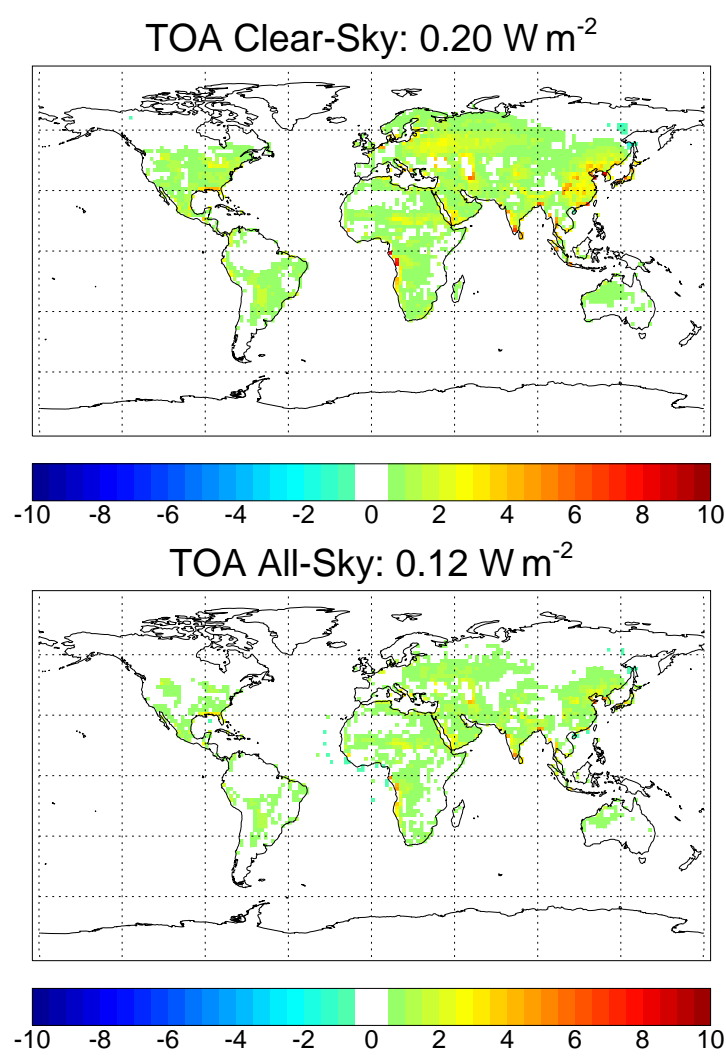

Fig. 9. Annual-mean difference of clear-sky and all-sky anthropogenic direct aerosol radiative forcings between simulations applying the upper (ALB-H) and lower (ALB-L) bound of the AeroCom land surface albedos given in Fig. 8.

turbations in the main anthropogenic source regions. However, without aerosol absorption the short-wave TOA forcings are universally negative and the positive forcings over extended regions in BB-M change their sign in TRANS. In the global annual mean, absorption acts to reduce the negative TOA short-wave anthropogenic aerosol forcing of BB-M by $0.26 \mathrm{~W} \mathrm{~m}^{-2}$ for the clear-sky and $0.34 \mathrm{~W} \mathrm{~m}^{-2}$ for the allsky case, as indicated by the differences between the TRANS and BB-M cases in Table 7.

\subsection{Long-wave aerosol radiative effects}

The simulated instantaneous year 2000 mean long-wave total aerosol radiative forcings from the BASE simulation are given in Fig. 10 and Table 7. The largest long-wave atmospheric aerosol net absorption occurs in the high-latitude storm track regions, owing to large sea salt and associated aerosol water burdens, and in the Saharan dust plume. The wind driven sea salt emissions are spatio-temporally correlated with storms and the associated clouds and water vapour. As the long-wave radiation in these regions is predominantly attenuated by the water vapour and cloud water, the all-sky 

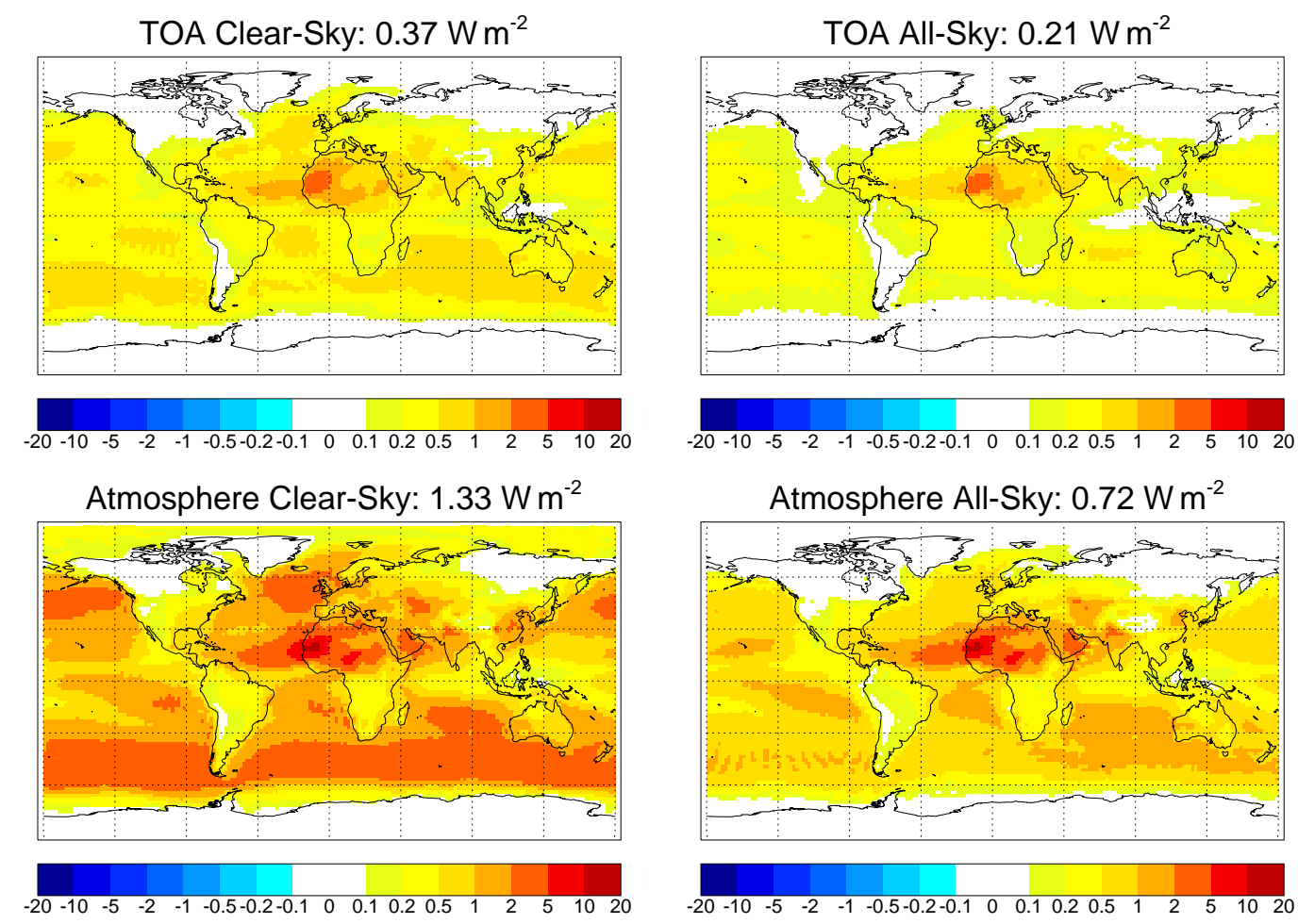

Fig. 10. Year 2000 instantaneous long-wave total aerosol TOA direct radiative forcing and atmospheric absorption from the BASE simulation.

long-wave aerosol absorption in the storm tracks becomes smaller compared to long-wave absorption in the predominantly clear-sky dust plume. Dust storms frequently lift mineral dust to high altitudes (e.g. Colarco et al., 2003), resulting in a higher mass fraction of DU at high altitudes than for sea salt (see Fig. 11 in Textor et al., 2006). Owing to the colder temperatures at high altitudes, it follows from StefanBoltzmann's law that less of the absorbed long-wave radiation is re-emitted than for low-altitude absorption that effectively re-emits at higher temperatures, similar to the underlying surface. Consequently, the long-wave aerosol radiative forcing at the TOA shows a maximum in the Saharan dust plume, reaching about $2-5 \mathrm{~W} \mathrm{~m}^{-2}$ in the annual mean. On a monthly mean basis, clear-sky long-wave TOA aerosol radiative forcings in the Saharan dust source region reach about $10-20 \mathrm{~W} \mathrm{~m}^{-2}$ (not shown), in good agreement with the satellite-derived estimate by Zhang and Christopher (2003). It needs to be emphasised that the present setup of ECHAM5-HAM does not include the super-coarse modes of mineral dust and sea salt (see Stier et al., 2005) so that the long-wave aerosol radiative effect of natural aerosols could be underestimated. However, owing to the short lifetime of super-coarse particles this effect is probably limited to the source regions.

As expected from theory, the simulated annual-mean longwave anthropogenic aerosol absorption $\left(0.03 \mathrm{~W} \mathrm{~m}^{-2}\right)$ and TOA radiative forcing $\left(0.02 \mathrm{~W} \mathrm{~m}^{-2}\right)$ are small (Fig. 11 , note the different scales) compared to the short-wave absorption and radiative forcings. Maxima of anthropogenic absorption and TOA forcing reach about 0.2 and $1 \mathrm{~W} \mathrm{~m}^{-2}$ in the main anthropogenic source regions, respectively.

4.5 Cloud radiative properties considering the effects of aerosol inclusions

Simulated aerosol and aerosol-cloud short-wave absorption optical depths from the simulation with the consideration of interstitial aerosols and black carbon inclusions on the cloud radiative properties CL-INC, the simulation with interstitial in-cloud aerosols but without the black carbon inclusion effect CL-INT, and the simulation with all in-cloud aerosol considered interstitial CL-EXT are given in Fig. 12. While the cloud absorption optical depth, i.e. the absorption optical depth of embedded aerosols, for pure water clouds in CLINT and CL-EXT is negligible, the consideration of black carbon inclusions for the cloud radiative properties in CLINC results in an inclusion AAOD of $0.6 \times 10^{-3}$. The consideration of all in-cloud aerosol as interstitial increases the interstitial AAOD in CL-EXT to $0.3 \times 10^{-3}$ as compared to $0.2 \times 10^{-3}$ in CL-INT and CL-INC.

From the simulated short-wave total aerosol atmospheric absorption differences between CL-INC and CL-INT given in Fig. 13, it is evident that the absorption by $\mathrm{BC}$ inclusions results in an all-sky absorption of $0.05 \mathrm{~W} \mathrm{~m}^{-2}$, with maxima 

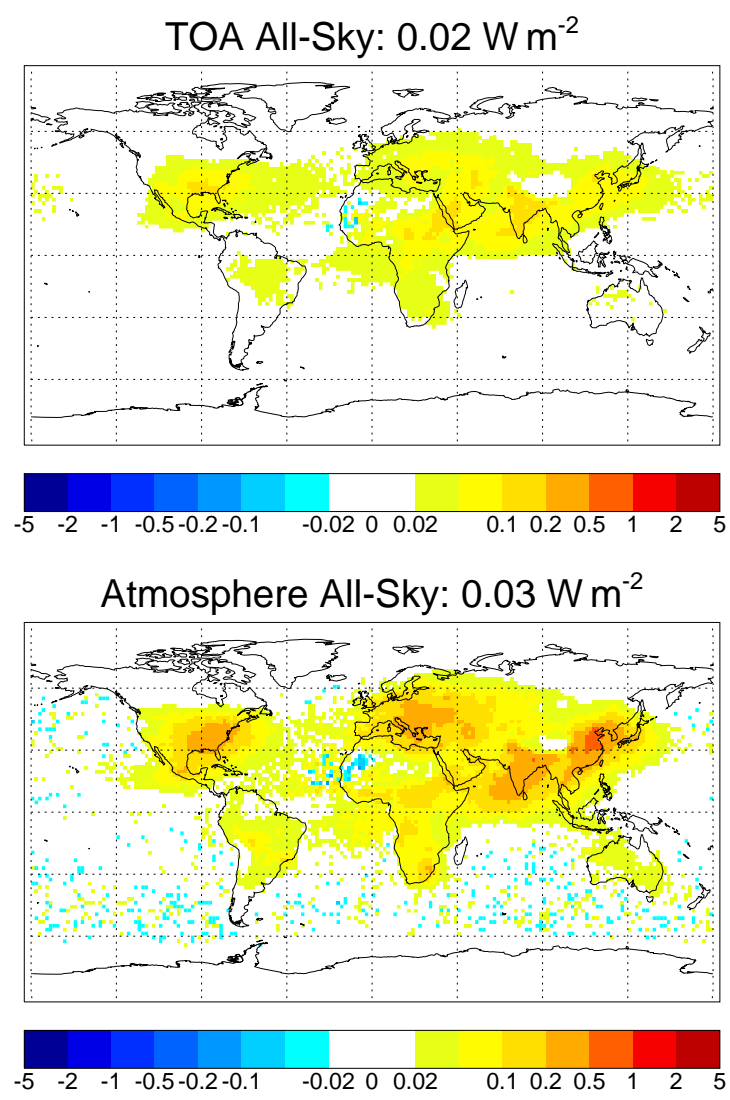

Fig. 11. Year 2000 instantaneous long-wave anthropogenic aerosol TOA direct radiative forcing and atmospheric absorption from the BASE simulation.

in regions with high inclusion AAODs. However, the absorption enhancement over the fully externally mixed in-cloud aerosol population trough comparison with the the difference of CL-EXT - CL-INT is very small.

The resulting short-wave TOA total aerosol forcing perturbation owing to $\mathrm{BC}$ inclusions, shown in Fig. 13 as the difference between CL-INC and CL-INT, is small with a global annual-mean of $0.02 \mathrm{~W} \mathrm{~m}^{-2}$. The TOA forcing perturbation owing to the consideration of all aerosols as an external mixture in CL-EXT as opposed to the case of only the interstitial residual in CL-INT, given as the difference between CL-EXT and CL-INC, shows small positive values in the regions with high AAODs and small negative values over regions with high hydrophilic aerosol burdens. This can be explained by the the fact that the effect of non $\mathrm{BC}$ aerosol components, such as sea salt, on the cloud radiative properties is generally considered small and was thus neglected in CL-INT while their effect is included in the fully externally mixed interstitial aerosol in CL-EXT. Thus, the enhanced scattering due to interstitial sea salt in CL-EXT results in the small negative forcing perturbation over the oceans.

\section{Conclusions}

We have presented a comprehensive examination of aerosol absorption with a focus on evaluating the sensitivity of the global distribution of aerosol absorption to key uncertainties in the process representation.

For this purpose we employed the aerosol-climate model ECHAM5-HAM with prognostic representation of the aerosol composition, size-distribution, and mixing-state (Stier et al., 2005) and extended it by:

- Alternative refractive indices for black carbon (Bond and Bergstrom, 2006) and extended look-up tables of the short-wave aerosol radiative properties covering a wider refractive index range.

- Alternative methods for the calculation of effective refractive indices of internally mixed modes based on the Bruggeman and Maxwell-Garnett effective medium approaches.

- A new look-up table approach for the ECHAM5 cloud radiative properties, considering the effect of aerosol inclusions in cloud droplets and ice crystals employing the Maxwell-Garnett effective medium approach.

- A long-wave aerosol radiation module in analogy to the short-wave look-up table approach.

- A module for the calculation of instantaneous aerosol forcing.

- Alternative lower- and upper-bound land surface-albedo datasets derived from the AeroCom aerosol model intercomparison forcing experiment submissions.

For our investigation of aerosol absorption we performed pairs of present day (2000) and pre-industrial (1750) simulations for BASE: as in Stier et al. (2005), BB-M: updated medium absorbing refractive indices from Bond and Bergstrom (2006), BB-H: updated highly absorbing refractive indices from Bond and Bergstrom (2006), BRUG: as BB-M but with Bruggeman (1935) mixing rule for effective refractive indices, ALB-L: as BB-M but employing a lower bound of currently used land-surface albedos derived from AeroCom, ALB-H: as BB-M but employing a higher bound of currently used land-surface albedos derived from AeroCom, CL-INC: as BB-M but with consideration of aerosol inclusions for cloud radiative properties.

Evaluation of the simulated aerosol absorption optical depth with retrievals from the AERONET sun-photometer network shows for all simulations a good agreement in the large scale global patterns with maxima in the biomass burning regions of Central Africa and South America, in the Saharan dust plume, and in regions with high anthropogenic activities over India and South East Asia. On a regional basis, general and seasonal biases, such as an underestimation of 
CL-INC

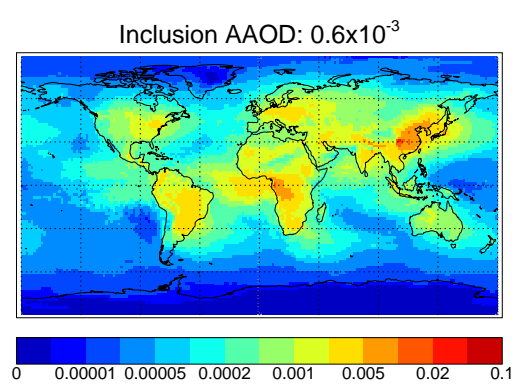

Interstitial AAOD: $0.2 \times 10^{-3}$

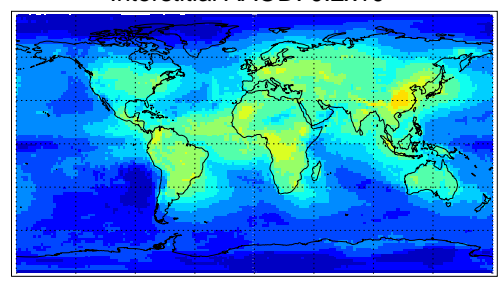

$\begin{array}{lllllll}0.00001 & 0.00005 & 0.0002 & 0.001 & 0.005 & 0.02 & 0.1\end{array}$
CL-INT

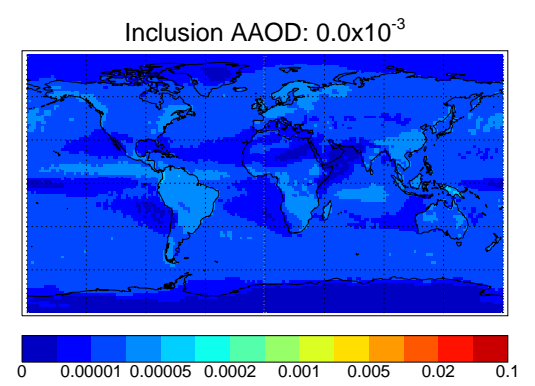

Interstitial AAOD: $0.2 \times 10^{-3}$

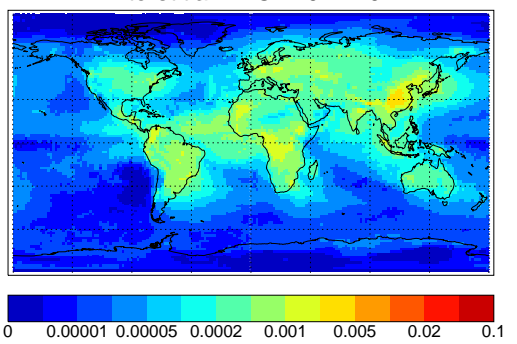

CL-EXT

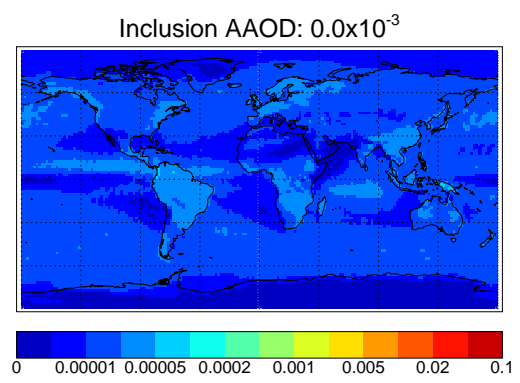

Interstitial AAOD: $0.3 \times 10^{-3}$

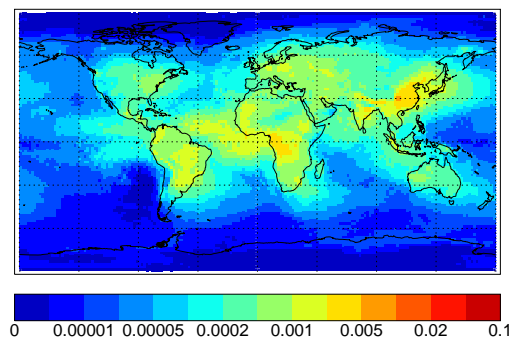

Fig. 12. Annual-mean in-cloud broad-band visible $(0.25-0.69 \mu \mathrm{m})$ aerosol absorption optical depths from the CL-INC, CL-INT, and CL-EXT simulations, integrated over the cloudy layers of the atmospheric column. Inclusion AAOD: inclusion aerosol AAOD, i.e. cloud absorption optical depth with consideration of black carbon inclusions; Interstitial: interstitial AAOD.

the AAOD at the urban Mexico City and central European sites, and differences among the simulations become evident. The spatio-temporally very inhomogeneous measurements do not seem to allow one to derive a global measure of the model performance. However, it becomes clear from the seasonal evaluation at 38 AERONET sites that the update of the BC refractive indices from Hess et al. (1998) to Bond and Bergstrom (2006) significantly improves the previous underestimation of AAOD in the BASE simulation. From this evaluation we conclude that the BB-M and the similar BRUG simulation seem to provide the best representation of the AERONET retrieved AAOD - for the black carbon emissions used in all ECHAM5-HAM simulations (Bond et al., 2004). It has to be pointed out that the retrieval of AAOD from AERONET measurements is subject to nonnegligible uncertainty, in particular for low AODs. However, it is arguably the most accurate measurement of ambient aerosol absorption available.

From comparison of the BB-M simulation with that simulation in which all aerosols are artificially made completely non-absorbing, we calculate that absorption acts to reduce the global annual-mean negative short-wave anthropogenic aerosol forcing of BB-M by $0.26 \mathrm{~W} \mathrm{~m}^{-2}(33 \%)$ for the clearsky and $0.34 \mathrm{~W} \mathrm{~m}^{-2}(72 \%)$ for the all-sky case.

Our results confirm that the basic assumptions about the $\mathrm{BC}$ refractive index play a key role for aerosol absorption and radiative forcing; changing it from the widely used values $n=1.75+0.44 i$ in BASE (Hess et al., 1998) to the medium absorbing values of $n=1.85+0.71 i$ recommended by Bond and Bergstrom (2006) (values at $\lambda=550 \mathrm{~nm}$ ) in BB-M alters the annual-mean short-wave anthropogenic aerosol forcing clear-sky from $-0.65 \mathrm{~W} \mathrm{~m}^{-2}$ to $-0.53 \mathrm{~W} \mathrm{~m}^{-2}$ and allsky from -0.27 to $-0.13 \mathrm{~W} \mathrm{~m}^{-2}$. By comparison, replacing the commonly used volume-weighted mixing for the calculation of the effective refractive indices for the internally mixed modes by the more accurate Bruggeman (1935) mixing rule changes the BB-M forcings only by $-0.06 \mathrm{~W} \mathrm{~m}^{-2}$ for clear skies and by $-0.05 \mathrm{~W} \mathrm{~m}^{-2}$ for all skies.

The effect of the enhanced aerosol absorption in BB$\mathrm{M}$, which shows better agreement with the AERONET retrieved aerosol absorption optical depth than BASE, to further reduce the negative aerosol radiative forcing is in contradiction to some recent, more negative, satellite-based estimates of anthropogenic TOA aerosol radiative forcings: Bellouin et al. (2005) report clear-sky $-1.9 \pm 0.3 \mathrm{~W} \mathrm{~m}^{-2}$ and all-sky $-0.8 \pm 0.1 \mathrm{~W} \mathrm{~m}^{-2}$; Chung et al. (2005) report clearsky $-1.08 \mathrm{~W} \mathrm{~m}^{-2}$ and all-sky $-0.35 \pm 0.25 \mathrm{~W} \mathrm{~m}^{-2}$; Yu et al. (2006) report clear-sky $-1.33 \pm 0.82 \mathrm{~W} \mathrm{~m}^{-2}$. It has to be pointed out that the used passive satellite sensors cannot retrieve aerosols in the presence of clouds, adding to the uncertainty of the all-sky satellite estimates.

However, not only uncertainties in the aerosol system itself affect estimates of aerosol radiative forcing. Other factors in its calculation also contribute to the large diversity in current aerosol forcing estimates. In particular, the surface albedo plays a crucial role as its value determines the sign of 

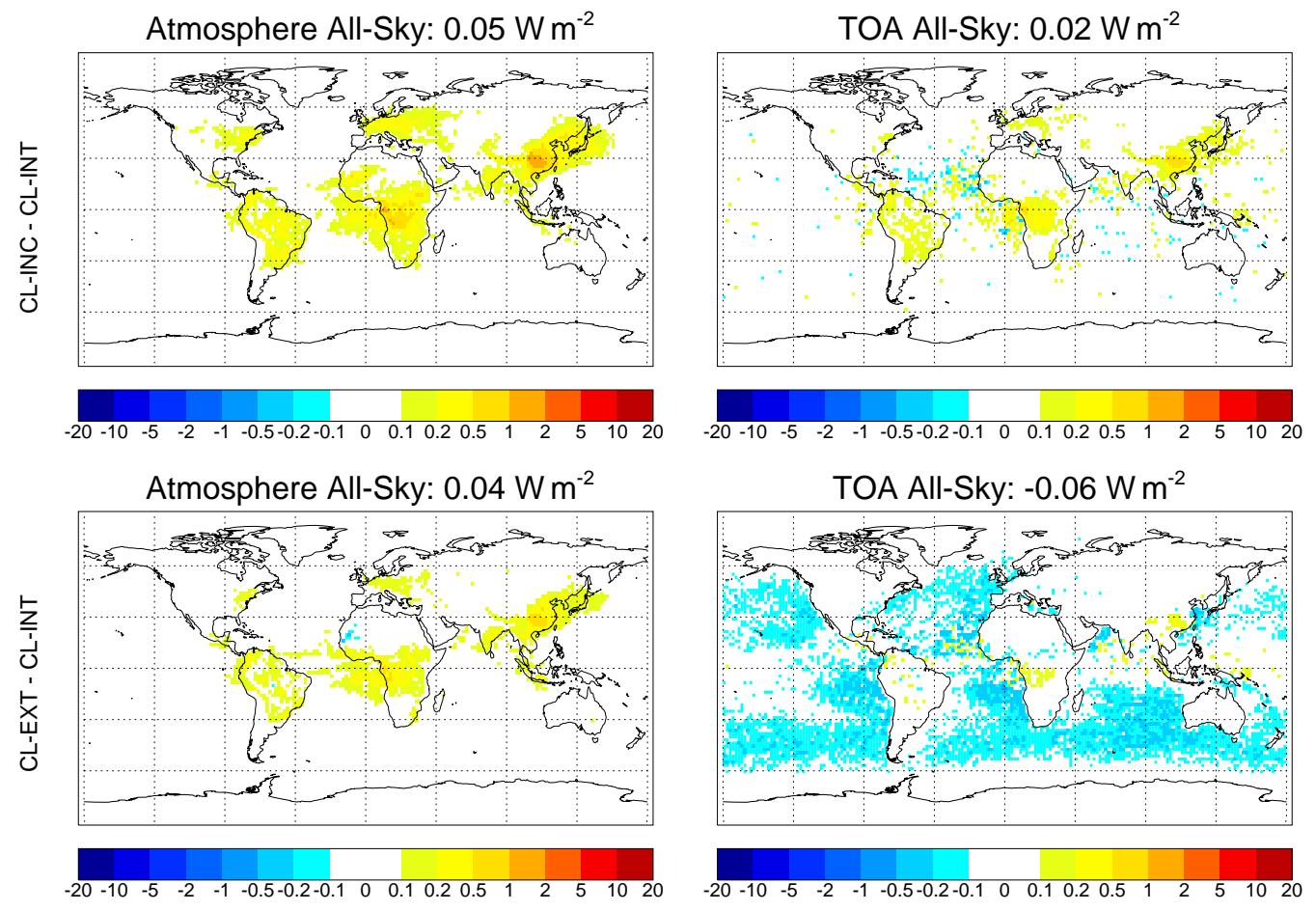

Fig. 13. Simulated year 2000 total aerosol all-sky short-wave atmospheric absorption and TOA radiative forcing differences between CL-INC and CL-INT and between CL-EXT and CL-INT.

the top-of-atmosphere aerosol radiative forcing for an aerosol column with given aerosol single scattering albedo. To quantify the effect of common assumptions for the surface albedo on aerosol absorption and radiative forcing, we replaced the land surface albedo field applied in BB-M by fields of the the upper and lower bound of the reported surface albedos in the AeroCom forcing experiment. Higher surface albedos result in a positive contribution of aerosol absorption to the TOA forcing so that it is reduced in the global annual-mean from -0.53 to $-0.42 \mathrm{~W} \mathrm{~m}^{-2}$ (clear-sky) and from -0.13 to $-0.06 \mathrm{~W} \mathrm{~m}^{-2}$ (all-sky) using the upper-bound surface albedo and enhanced from -0.53 to $-0.61 \mathrm{~W} \mathrm{~m}^{-2}$ (clear-sky) and from -0.13 to $-0.18 \mathrm{~W} \mathrm{~m}^{-2}$ (all-sky) using the lower-bound of the surface albedo fields. It needs to be emphasised that also the ocean surface albedo and its implementation in current aerosol forcing calculations is subject to considerable uncertainty, as indicated by a large diversity in the AeroCom submissions. However, owing to ambiguities in the diagnostics of the AeroCom submissions we refrained to include the ocean albedos in our sensitivity study so that the simulated global mean forcing diversity is likely to be a lower estimate.

The anthropogenic long-wave aerosol radiative effects predict a global annual-mean absorption of $0.06 \mathrm{~W} \mathrm{~m}^{-2}$ (clear-sky) and $0.03 \mathrm{~W} \mathrm{~m}^{-2}$ (all-sky) and a TOA forcing of $0.03 \mathrm{~W} \mathrm{~m}^{-2}$ (clear-sky) and $0.02 \mathrm{~W} \mathrm{~m}^{-2}$ (all-sky), negligible, as expected from the typical sub-micron size of anthropogenic aerosols. For the larger natural dust and sea-salt aerosols, long-wave radiative effects become of importance so that the long-wave total aerosol absorption is $1.33 \mathrm{~W} \mathrm{~m}^{-2}$ (clear-sky) and $0.72 \mathrm{~W} \mathrm{~m}^{-2}$ (all-sky) while the TOA forcing is $0.37 \mathrm{~W} \mathrm{~m}^{-2}$ (clear-sky) and $0.21 \mathrm{~W} \mathrm{~m}^{-2}$ (all-sky). However, the present setup of ECHAM5-HAM does not include the super-coarse modes of mineral dust and sea salt so that the long-wave aerosol radiative effect of natural aerosols close to the source regions could be underestimated. A version of ECHAM5-HAM including super-coarse aerosols is in development and will allow one to quantify these effects in the near future.

As previous studies indicated (Chuang et al., 2002; Liu et al., 2002), the simulated effect of absorption by aerosol inclusions embedded in cloud droplets and ice crystals on the global radiation budget is small. The global annual-mean total aerosol short-wave AAOD of BC inclusions in clouds is $0.6 \times 10^{-3}$, resulting in an absorption of $0.05 \mathrm{~W} \mathrm{~m}^{-2}$ and a positive TOA forcing perturbation of $0.02 \mathrm{~W} \mathrm{~m}^{-2}$. In published literature AODs and AAODs are generally reported as "clear-sky" without a precise definition. Our results indicate that a more detailed diagnostics of these quantities, separate for clear-sky and cloudy-sky cases, might improve the understanding about the diversity of aerosol radiative effects in current models and remote sensing products.

We intentionally did not address two key uncertainties in estimates of aerosol absorption and radiative forcing in this study: the uncertainty associated with emission inventories, 
which has been extensively discussed in the respective literature and the radiative effects of mixing of $\mathrm{BC}$ by microphysical interaction with other aerosol components, that we have scrutinised in previous work. Uncertainties of the mass of present day $\mathrm{BC}$ emissions are estimated globally to be at least a factor of two with fossil fuels emissions ranging from $2.8 \mathrm{Tg}(\mathrm{C}) \mathrm{yr}^{-1}$ to 8.0 (see Bond et al., 2004; Ito and Penner, 2005, and references therein) and wildfire emissions ranging from $1.8 \mathrm{Tg}(\mathrm{C}) \mathrm{yr}^{-1}$ (year 2000 estimate, Hoelzemann et al., 2004) to $7.1 \mathrm{Tg}(\mathrm{C}) \mathrm{yr}^{-1}$ (year 1997 estimate, Generoso et al., 2003). Robust estimates of emission size distributions representative for global modelling studies are generally not available, resulting in a significantly larger uncertainty in the emission number flux of primary $\mathrm{BC}$ particles. These uncertainties directly propagate into simulations of the aerosol absorption and radiative effects. However, without tighter constraints on atmospheric aerosol radiative properties, ambiguities will not allow one to use absorption measurements to improve the emission inventories by forward or inverse modelling. The radiative implications of mixing of $\mathrm{BC}$ with other aerosol components are more complex than is frequently portrayed. The mixing with nonabsorbing, hydrophilic aerosols, such as sulfate, affects atmospheric absorption in opposing ways: increasing absorption through enhancement of the BC absorption efficiency by internal mixing, but also decreasing absorption through ageing initially hydrophobic BC to a hydrophilic state, enhancing its removal by wet scavenging, and consequently decreasing BC lifetime and abundance (Stier et al., 2006c).
Our analysis of the effect of the use of different landsurface albedo in current modelling studies highlights that uncertainties in the host model parameters, independent of the uncertainty associated with the aerosol simulations, can significantly contribute to the large diversity in current estimates of aerosol radiative effects. The estimated uncertainties would be even larger if the differing assumptions in the sea surface albedo or variations in the cloud fields could have been taken into account.

The demonstrated uncertainties related to assumptions in current aerosol models and satellite forcing retrievals could be quantified in an inter-comparison study with prescribed aerosol radiative properties.

Although the ECHAM5-HAM aerosol-climate model is advanced in terms of the aerosol representation, large uncertainties remain, such as the aerosol mixing state and the representation of aerosol-cloud interactions. Size-resolved measurements of the aerosol mixing state at various global locations are required as benchmark for microphysical aerosol models with prognostic mixing state. This will allow to test and refine the aerosol representation in global aerosol models and satellite retrievals, thus improve quantitative estimates of the climate impact of aerosol absorption. 


\section{Appendix A}

Scatterplots of the daily-mean simulated and AERONET retrieved absorption optical depth for the BB-M sensitivity study in Fig. 4
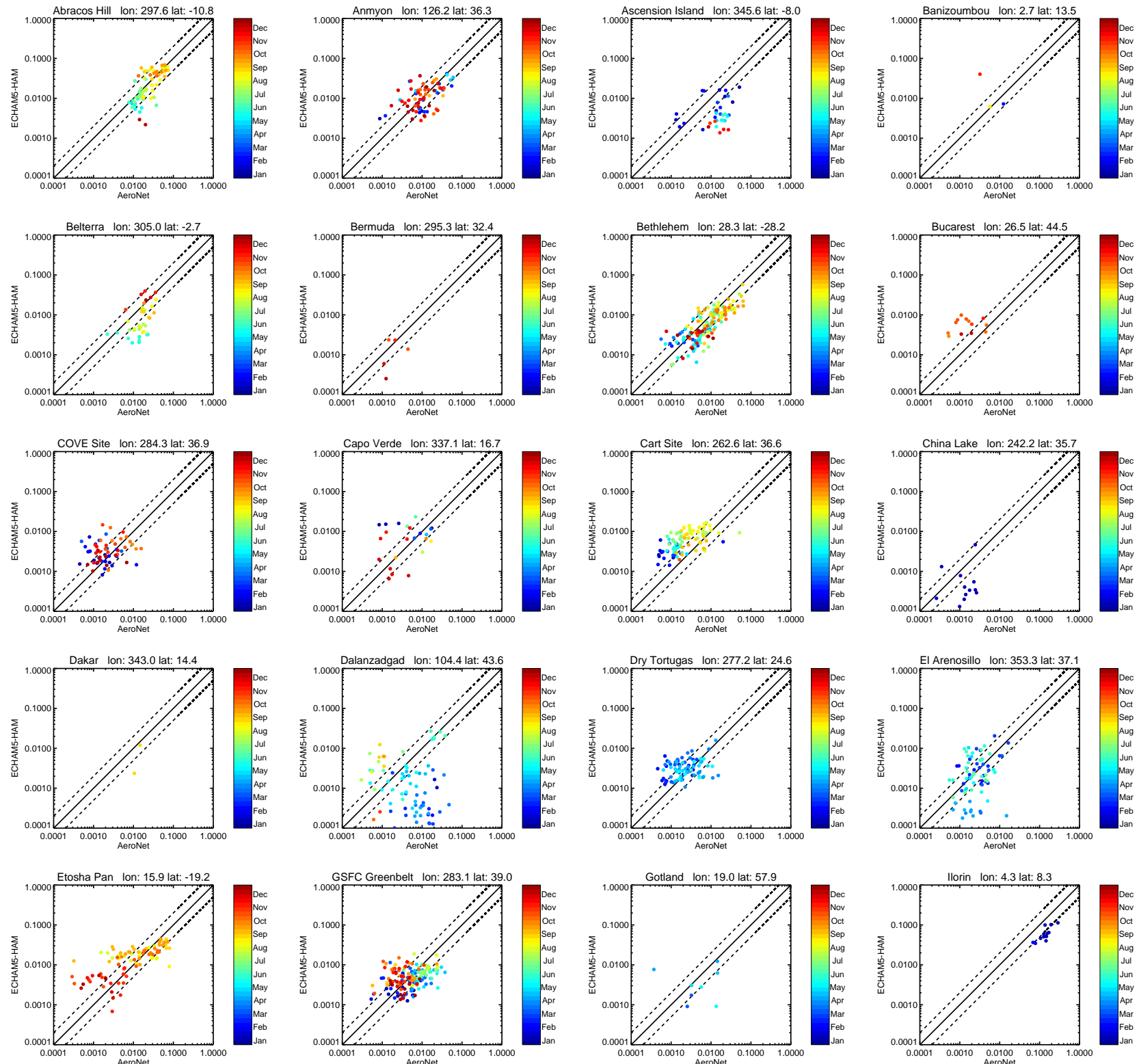

Fig. A1. Scatterplots of year 2000 daily-mean ECHAM5-HAM simulated and AERONET retrieved absorption optical depth at wavelength $\lambda=550 \mathrm{~nm}$ for the BB-M simulation as used in Fig. 4b. The ECHAM5-HAM output is sampled for each measurement date at the model grid box containing the measurement station. The seasonality is colour coded.

Acknowledgements. This research was supported by the NASA Earth Observing System Interdisciplinary Science Program (NASA EOSIDS). The simulations were performed at the German High Performance Computing Centre for Climate- and Earth System Research. We would like to thank D. Koch (Goddard Institute for Space Studies, USA), S. Reddy (NOAA Geophysical Fluid Dynamics Laboratory, USA), M. Schulz (Laboratoire des Sciences du Climat et de l'Environnement, France), A. Kirkevåg and T. Iversen (University of Oslo, Norway), X. Liu and J. E. Penner (University of Michigan, USA), and T. Takemura (Kyushu University, Japan) for making their surface albedo data submitted to AeroCom available and M. Schulz additionally for his support with the AeroCom data. We further thank the principal investigators and their staff for establishing and maintaining the AERONET sites used in this investigation.

Edited by: R. von Glasow 

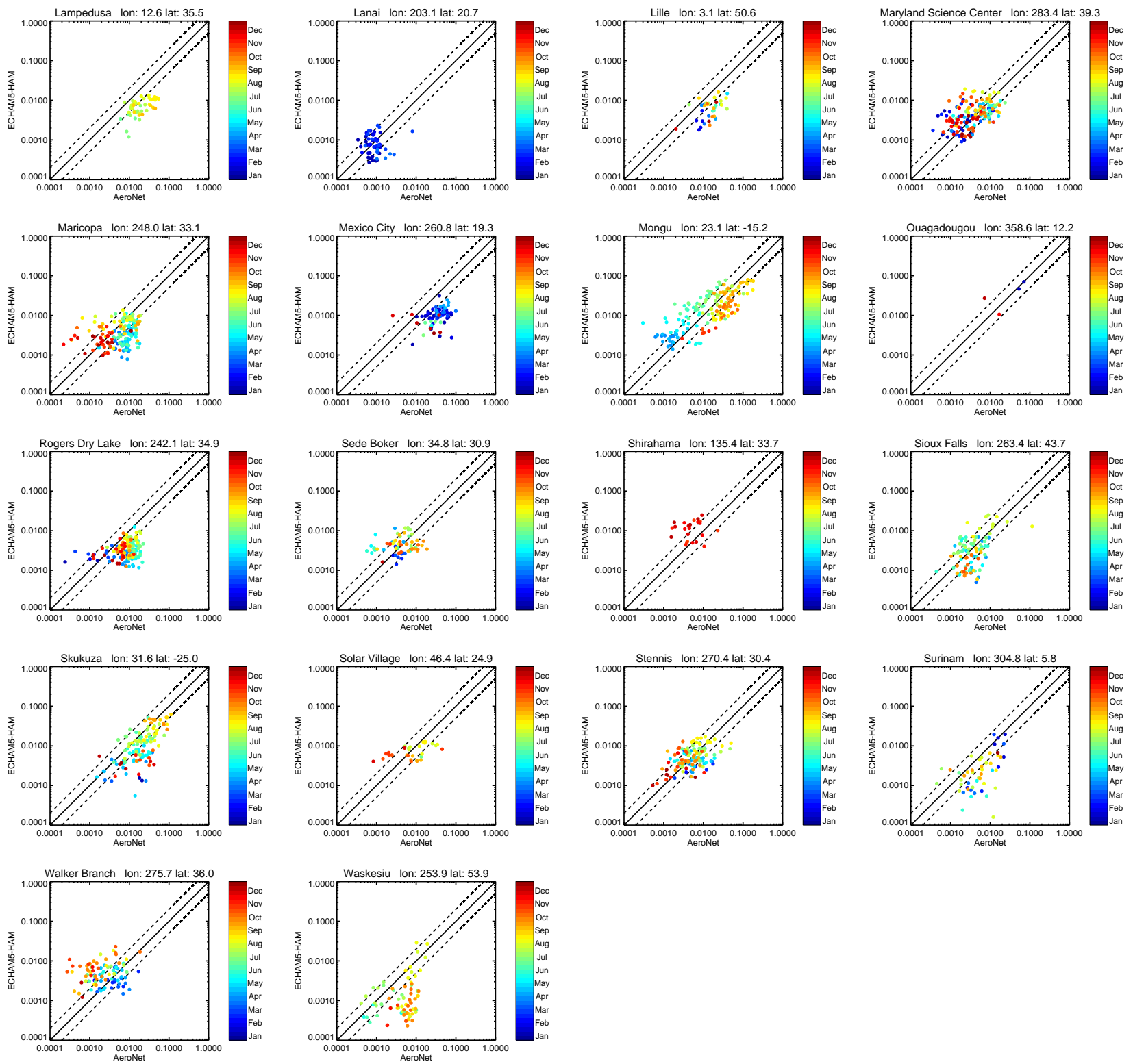

Fig. A1. Continued.

\section{References}

Ackerman, A., Toon, O., Stevens, D., Heymsfield, A., Ramanathan, V., and Welton, E.: Reduction of tropical cloudiness by soot, Science, 288, 1042-1047, 2000.

Ackerman, T. P. and Toon, O. B.: Absorption of visible radiation in atmosphere containing mixtures of absorbing and non-absorbing particles, Appl. Opt., 20, 3661-3668, 1981.

Albrecht, B. A.: Aerosols, cloud microphysics, and fractional cloudiness, Science, 245, 1227-1230, 1989.

Andreae, M. O. and Gelencsér, A.: Black carbon or brown carbon? The nature of light-absorbing carbonaceous aerosols, Atmos. Chem. Phys., 6, 3131-3148, 2006,

http://www.atmos-chem-phys.net/6/3131/2006/.

Ångström, A.: Atmospheric turbidity, global illumination and planetary albedo of the earth, Tellus, 14, 435-450, 1962.

Aspnes, D. E.: Local-field effects and effective-medium theory: A microscopic perspective, Am. J. Phys., 50, 704-709, 1982.

Bakan, S., Chlond, A., Cubasch, U., Feichter, J., Graf, H., Grassl, H., Hasselmann, K., Kirchner, I., Latif, M., Roeckner, E., Sausen, R., Schlese, U., Schriever, D., Schult, I., Schumann, U., Sielmann, F., and Welke, W.: Climate response to smoke from the burning oil-wells in Kuwait, Nature, 351, 367-371, 1991.

Balkanski, Y., Schulz, M., Claquin, T., and Guibert, S.: Reevaluation of mineral aerosol radiative forcings suggests a better agreement with satellite and AERONET data, Atmos. Chem. Phys., 7, 
81-95, 2007,

http://www.atmos-chem-phys.net/7/81/2007/.

Bellouin, N., Boucher, O., Haywood, J., and Reddy, M. S.: Global estimate of aerosol direct radiative forcing from satellite measurements, Nature, 438, 1138-1141, doi:10.1038/nature04348, 2005.

Bohren, C. F. and Huffman, D. R.: Absorption and scattering of light by small particles, Wiley Professional Paperback Series, Wiley-Interscience, New York, USA, 1998.

Bond, T. C. and Bergstrom, R. W.: Light absorption by carbonaceous particles: An investigative review, Aerosol Sci. Technol., 40, 27-67, doi:10.1080/02786820500421521, 2006.

Bond, T. C. and Sun, H.: Can reducing black carbon emissions counteract global warming?, Environ. Sci. Technol., 39, 59215926, 2005.

Bond, T. C., Streets, D. G., Yarber, K. F., Nelson, S. M., Woo, J.H., and Klimont, Z.: A technology-based global inventory of black and organic carbon emissions from combustion, J. Geophys. Res., 109, D14203, doi:10.1029/2003JD003697, 2004.

Bruggeman, D.: Calculation of various physics constants in heterogenous substances i dielectricity constants and conductivity of mixed bodies from isotropic substances, Annalen der Physik, 24, 636-664, 1935.

Chuang, C. C., Penner, J. E., Prospero, J. M., Grant, K. E., Rau, G. H., and Kawamoto, K.: Cloud susceptibility and the first aerosol indirect forcing: Sensitivity to black carbon and aerosol concentrations, J. Geophys. Res., 107, 4564, doi:10.1029/2000JD000 215, 2002.

Chung, C. E., Ramanathan, V., Kim, D., and Podgorny, I. A.: Global anthropogenic aerosol direct forcing derived from satellite and ground-based observations, J. Geophys. Res., 110, D24207, doi:10.1029/2005JD006356, 2005.

Chung, S. H. and Seinfeld, J. H.: Global distribution and climate forcing of carbonaceous aerosols, J. Geophys. Res., 107, 4407, doi:10.1029/2001JD001397, 2002.

Chung, S. H. and Seinfeld, J. H.: Climate response of direct radiative forcing of anthropogenic black carbon, J. Geophys. Res., 110, D11102, doi:10.1029/2004JD005441, 2005.

Chýlek, P., Videen, G., Ngo, D., Pinnick, R., and Klett, J.: Effect of black carbon on the optical-properties and climate forcing of sulfate aerosols, J. Geophys. Res., 100, 16325-16332, 1995.

Chýlek, P., Lesins, G. B., Videen, G., Wong, J., G.Pinnick, R., Ngo, D., and Klett, J. D.: Black carbon and absorption of solar radiation by clouds, J. Geophys. Res., 101, 23 365-23 371, 1996.

Chýlek, P., Videen, G., Wally Geldart, D., Dobbie, J. S., and Tso, H. W.: Light scattering by nonspherical particles: Theory, measurements, and applications, chap. Effective medium appoximations for heterogeneous particles, Accademic Press, San Diego, USA, 273-308, 2000.

Colarco, P. R., Toon, O. B., Reid, J. S., Livingston, J. M., Russell, P. B., Redemann, J., Schmid, B., Maring, H. B., Savoie, D., Welton, E. J., Campbell, J. R., Holben, B. N., and Levy, R.: Saharan dust transport to the Caribbean during PRIDE: 2. Transport, vertical profiles, and deposition in simulations of in situ and remote sensing observations, J. Geophys. Res., 108, 8590, doi:10.1029/2002JD002659, 2003.

Cooke, W. F.: Fossil fuel \& biomass burning black carbon emissions, GEIA-Webpage: http://www.geiacenter.org, GEIA Global Emissions Inventory Activity, 1997.
Cooke, W. F. and Wilson, J. J. N.: A global black carbon aerosol model, J. Geophys. Res., 101, 19395-19410, doi:10.1029/96JD00671, 1996.

Cooke, W. F., Koffi, B., and Gregoire, J.-M.: Seasonality of vegetation fires in Africa from remote sensing data and application to a global chemistry model, J. Geophys. Res., 101, 21 051-21 065, 1996.

Cooke, W. F., Liousse, C., Cachier, H., and Feichter, J.: Construction of a $1^{\circ} \times 1^{\circ}$ fossil fuel emission data set for carbonaceous aerosol and implementation and radiative impact in the ECHAM4 model, J. Geophys. Res., 104, 22 137-22 162, 1999.

Dentener, F., Kinne, S., Bond, T., Boucher, O., Cofala, J., Generoso, S., Ginoux, P., Gong, S., Hoelzemann, J. J., Ito, A., Marelli, L., Penner, J. E., Putaud, J.-P., Textor, C., Schulz, M., van der Werf, G. R., and Wilson, J.: Emissions of primary aerosol and precursor gases in the years 2000 and 1750, prescribed data-sets for AeroCom, Atmos. Chem. Phys., 6, 4321-4344, 2006, http://www.atmos-chem-phys.net/6/4321/2006/.

Downing, H. D. and Williams, D.: Optical-constants of water in infrared, J. Geophys. Res., 80, 1656-1661, 1975.

Dubovik, O. and King, M. D.: A flexible inversion algorithm for retrieval of aerosol optical properties from sun and sky radiance measurements, J. Geophys. Res., 105, 20 673-20 696, 2000.

Feichter, J., Kjellström, E., Rodhe, H., Dentener, F., Lelieveld, J., and Roelofs, G.-J.: Simulation of the tropospheric sulfur cycle in a global climate model, Atmos. Environ., 30, 1693-1707, 1996.

Fouquart, Y. and Bonnel, B.: Computations of solar heating of the earth's atmosphere: A new parameterization, Beitr. Phys. Atmos., 53, 35-62, 1980.

Ganzeveld, L. N., van Aardenne, J. A., Butler, T. M., Lawrence, M. G., Metzger, S. M., Stier, P., Zimmermann, P., and Lelieveld, J.: Technical Note: Anthropogenic and natural offline emissions and the online EMissions and dry DEPosition submodel EMDEP of the Modular Earth Submodel system (MESSy), Atmos. Chem. Phys. Discuss., 6, 5457-5483, 2006,

http://www.atmos-chem-phys-discuss.net/6/5457/2006/.

Garnett, J.: Colours in metal glasses and in metallic films, Philos. Trans. R. Soc. London, 203, 385-420, 1904.

Garnett, J. C. M.: Colours in metal glasses, in metallic films, and in metallic solutions - II, Philos. Trans. R. Soc. London, 205, 237-288, 1906.

Generoso, S., Bréon, F.-M., Balkanski, Y., Boucher, O., and Schulz, M.: Improving the seasonal cycle and interannual variations of biomass burning aerosol sources, Atmos. Chem. Phys., 3, 12111222, 2003, http://www.atmos-chem-phys.net/3/1211/2003/.

Hagemann, S.: An improved land surface parameter dataset for global and regional climate models, MPI-Report 336, Max Planck Institute for Meteorology, Hamburg, Germany, available from http://www.mpimet.mpg.de, 2002.

Hansen, J., Sato, M., Nazarenko, L., Ruedy, R., Lacis, A., Koch, D., Tegen, I., Hall, T., Shindell, D., Santer, B., Stone, P., Novakov, T., Thomason, L., Wang, R., Wang, Y., Jacob, D., Hollandsworth, S., Bishop, L., Logan, J., Thompson, A., Stolarski, R., Lean, J., Willson, R., Levitus, S., Antonov, J., Rayner, N., Parker, D., and Christy, J.: Climate forcings in Goddard Institute for Space Studies SI2000 simulations, J. Geophys. Res., 107, 4347, doi:10.1029/2001JD001143, 2002.

Hansen, J. E. and Travis, L. D.: Light scattering in planetary atmo- 
spheres, Space Science Reviews, 16, 527-610, 1974.

Hansen, J. E., Sato, M., and Ruedy, R.: Radiative forcing and climate response, J. Geophys. Res., 102, 6831-6864, 1997.

Haywood, J. M. and Shine, K. P.: The effect of anthropogenic sulfate and soot on the clear-sky planetary radiation budget, Geophys. Res. Lett., 22, 603-606, 1995.

Hess, M., Koepke, P., and Schult, I.: Optical properties of aerosols and clouds: The software package OPAC, B. Am. Meteorol. Soc., 79, 831-844, 1998.

Hoelzemann, J. J., Schultz, M. G., Brasseur, G. P., Granier, C., and Simon, M.: Global Wildland Fire Emission Model (GWEM): Evaluating the use of global area burnt satellite data, J. Geophys. Res., 109, D14S04, doi:10.1029/2003JD003666, 2004.

Holben, B., Eck, T., Slutsker, I., Tanre, D., Buis, J., Setzer, A., Vermote, E., Reagan, J., Kaufman, Y., Nakajima, T., Lavenu, F., Jankowiak, I., and Smirnov, A.: AERONET - A federated instrument network and data archive for aerosol characterization, Rem. Sens. Environ., 66, 1-16, 1998.

Holben, B. N., Tanré, D., Smirnov, A., Eck, T. F., Slutsker, I., Abuhassan, N., Newcomb, W. W., Schafer, J. S., Chatenet, B., Lavenu, F., Kaufman, Y. J., Castle, J. V., Setzer, A., Markham, B., Frouin, D. C. R., Halthore, R., Karneli, A., O’Neill, N. T., Pietras, C., Pinker, R. T., Voss, K., and Zibordi, G.: An emerging ground-based aerosol climatology: Aerosol optical depth from AERONET, J. Geophys. Res., 106, 12 067-12 098, 2001.

Ito, A. and Penner, J. E.: Historical emissions of carbonaceous aerosols from biomass and fossil fuel burning for the period 1870-2000, Global Biogeochem. Cycles, 19, GB2028, doi:10.1029/2004GB002374, 2005.

Iversen, T. and Seland, Ø.: A scheme for process-tagged SO4 and BC aerosols in NCAR-CCM3. Validation and sensitivity to cloud processes, J. Geophys. Res., 107, 4751, doi:10.1029/2001JD000885, 2002.

Iversen, T. and Seland, $\varnothing$.: Correction to "A scheme for processtagged SO4 and BC aerosols in NCAR-CCM3. Validation and sensitivity to cloud processes", J. Geophys. Res., 108, 4502, doi:10.1029/2003JD003840, 2003.

Jacobson, M. Z.: A physically-based treatment of elemental carbon optics: Implications for global direct forcing of aerosols, Geophys. Res. Lett., 27, 217-220, 2000.

Jacobson, M. Z.: GATOR-GCMM: A global- through urban-scale air pollution and weather forecast model, 1. Model design and treatment of subgrid soil, vegetation, roads, rooftops, water, sea ice, and snow, J. Geophys. Res., 106, 5385-5402, 2001.

Jacobson, M. Z.: Control of fossil-fuel particulate black carbon and organic matter, possibly the most effective method of slowing global warming, J. Geophys. Res., 107, 4410, doi:10.1029/2001JD001376, 2002.

Jeuken, A. B. M., Siegmund, P. C., Heijboer, L. C., Feichter, J., and Bengtsson, L.: On the potential of assimilating meteorological analyses in a global climate model for the purpose of model validation, J. Geophys. Res., 101, 16939-16950, doi:10.1029/96JD01218, 1996.

Johnson, D. W.: ECMWF Workshop on 'Parameterization of the cloud topped boundary layer, chap. Parameterization of the cloud topped boundary layer: Aircraft measurements, ECMWF, Reading, UK, 77-117, 1993.

Kettle, A. and Andreae, M.: Flux of the dimethylsulfide from the oceans: A comparison of updated data sets and flux models, J.
Geophys. Res., 105, 26 793-26 808, 2000.

Kinne, S., Lohmann, U., Feichter, J., Schulz, M., Timmreck, C., Ghan, S., Easter, R., Chin, M., Ginoux, P., Takemura, T., Tegen, I., Koch, D., Herzog, M., Penner, J., Pitari, G., Holben, B., Eck, T., Smirnov, A., Dubovik, O., Slutsker, I., Tanre, D., Torres, O., Mishchenko, M., Geogdzhayev, I., Chu, D. A., and Kaufman, Y.: Monthly averages of aerosol properties: A global comparison among models, satellite data, and AERONET ground data, $\mathrm{J}$ Geophys. Res., 108, 4634, doi:10.1029/2001JD001253, 2003.

Kinne, S., Schulz, M., Textor, C., Guibert, S., Balkanski, Y., Bauer, S. E., Berntsen, T., Berglen, T. F., Boucher, O., Chin, M., Collins, W., Dentener, F., Diehl, T., Easter, R., Feichter, J., Fillmore, D., Ghan, S., Ginoux, P., Gong, S., Grini, A., Hendricks, J., Herzog, M., Horowitz, L., Isaksen, I., Iversen, T., Kirkevåg, A., Kloster, S., Koch, D., Kristjansson, J. E., Krol, M., Lauer, A., Lamarque, J. F., Lesins, G., Liu, X., Lohmann, U., Montanaro, V., Myhre, G., Penner, J., Pitari, G., Reddy, S., Seland, O., Stier, P., Takemura, T., and Tie, X.: An AeroCom initial assessment - optical properties in aerosol component modules of global models, Atmos. Chem. Phys., 6, 1815-1834, 2006,

http://www.atmos-chem-phys.net/6/1815/2006/.

Kirkevåg, A. and Iversen, T.: Global direct radiative forcing by process-parameterized aerosol optical properties, J. Geophys. Res., 107, 4433, doi:10.1029/2001JD000886, 2002.

Kirkevåg, A., Iversen, T., Seland, Ø., and Kristjánsson, J. E.: Revised schemes for aerosol optical parameters and cloud condensation nuclei in CCM-Oslo, Institute Report Series ISBN 8291885-31-1, ISSN 1501-6854-128, Department of Geosciences, University of Oslo, 29 pp., 2005.

Koch, D., Schmidt, G. A., and Field, C. V.: Sulfur, sea salt, and radionuclide aerosols in GISS ModelE, J. Geophys. Res., 111, D06206, doi:10.1029/2004JD005550, 2006.

Lesins, G., Chýlek, P., and Lohmann, U.: A study of internal and external mixing scenarios and its effect on aerosol optical properties and direct radiative forcing, J. Geophys. Res., 107, 4094, doi:10.1029/2001JD000973, 2002.

Lin, S. J. and Rood, R. B.: Multidimensional flux form semiLagrangian transport, Mon. Wea. Rev., 124, 2046-2068, 1996.

Liousse, C., Penner, J. E., Chuang, C., Walton, J. J., Eddleman, H., and Cachier, H.: A global three-dimensional model study of carbonaceous aerosols, J. Geophys. Res., 101, 19411-19432, 1996.

Liu, L., Mishchenko, M., Menon, S., Macke, A., and Lacis, A.: The effect of black carbon on scattering and absorption of solar radiation by cloud droplets, J. Quant. Spectrosc. Ra., 74, 195-204, 2002.

Liu, X., Penner, J. E., and Herzog, M.: Global modeling of aerosol dynamics: Model description, evaluation, and interactions between sulfate and nonsulfate aerosols, J. Geophys. Res., 110, D18206, doi:10.1029/2004JD005674, 2005.

Lohmann, U. and Feichter, J.: Global indirect aerosol effects: a review, Atmos. Chem. Phys., 5, 715-737, 2005, http://www.atmos-chem-phys.net/5/715/2005/.

Lohmann, U. and Roeckner, E.: Design and performance of a new cloud microphysics scheme developed for the ECHAM4 general circulation model, Clim. Dynam., 12, 557-572, 1996.

Lohmann, U., Stier, P., Hoose, C., Ferrachat, S., Roeckner, E., and Zhang, J.: Cloud microphysics and aerosol indirect effects in the global climate model ECHAM5-HAM, Atmos. Chem. Phys., 7, 3425-3446, 2007, 
http://www.atmos-chem-phys.net/7/3425/2007/.

Mahowald, N. and Luo, C.: A less dusty future?, Geophys. Res. Lett., 30, 1903, doi:10.1029/2003GL017880, 2003.

Mahowald, N. M., Rivera, G. D. R., and Luo, C.: Comment on "Relative importance of climate and land use in determining present and future global soil dust emission", Geophys. Res. Lett., 31, L24105, doi:10.1029/2004GL021272, 2004.

Martins, J. V., Artaxo, P., Liousse, C., Reid, J. S., Hobbs, P. V., and Kaufman, Y. J.: Effects of black carbon content, particle size, and mixing on light absorption by aerosols from biomass burning in Brazil, J. Geophys. Res., 103, 32 041-32 050, 1998 a.

Martins, J. V., Hobbs, P. V., Weiss, R. E., and Artaxo, P.: Sphericity and morphology of smoke particles from biomass burning in Brazil, J. Geophys. Res., 103, 32 051-32 057, 1998 b.

McCormic, R. A. and Ludwig, J. H.: Climate modifications by atmospheric aerosols, Science, 156, 1358-1359, 1967.

Menon, S., Hansen, J., Nazarenko, L., and Luo, Y.: Climate effects of black carbon aerosols in China and India, Science, 297, 22502253, 2002.

Mikhailov, E. F., Vlasenko, S. S., Podgorny, I. A., Ramanathan, V., and Corrigan, C. E.: Optical properties of soot-water drop agglomerates: An experimental study, J. Geophys. Res., 111, D07209, doi:10.1029/2005JD006389, 2006.

Mlawer, E. J., Taubman, S. J., Brown, P. D., Iacono, M. J., and Clough, S. A.: Radiative transfer for inhomogeneous atmospheres: RRTM, a validated correlated-k model for the longwave, J. Geophys. Res., 102, 16 663-16682, 1997.

Morcrette, J.-J., Clough, S. A., Mlawer, E. J., and Iacono, M. J.: Impact of a validated radiative transfer scheme, RRTM, on the ECMWF model climate and 10-day forecasts, Technical Memorandum 252, ECMWF, Reading, UK, 48 pp., 1998.

Myhre, G., Berntsen, T. K., Haywood, J. M., Sundet, J. K., Holben, B. N., Johnsrud, M., and Stordal, F.: Modeling the solar radiative impact of aerosols from biomass burning during the Southern African Regional Science Initiative (SAFARI-2000) experiment, J. Geophys. Res., 108, 8501, doi:10.1029/2002JD002313, 2003.

Myhre, G., Stordal, F., Berglen, T., Sundet, J., and Isaksen, I.: Uncertainties in the radiative forcing due to sulfate aerosols, J. Atmos. Sci., 61, 485-498, 2004.

Nightingale, P., Malin, G., Law, C., Watson, A., Liss, P., Liddicoat, M., Boutin, J., and Upstill-Goddard, R.: In situ evaluation of airsea gas exchange parameterizations using novel conservative and volatile tracers, Global Biogeochem. Cy., 14, 373-387, 2000.

Nilsson, B.: Meteorological influence on aerosol extinction in the 0.2-40 $\mu \mathrm{m}$ wavelength range, Appl. Opt., 18, 3457-3473, 1979.

Nordeng, T. E.: Extended versions of the convective parameterization scheme at ECMWF and their impact on the mean and transient activity of the model in the tropics, Technical Memorandum 206, ECMWF, Reading, UK, 42 pp., 1994.

Pham, M., J.-F.Muller, Brasseur, G., Granier, C., and Megie, G.: A three-dimensional study of the tropospheric sulfur cycle, J. Geophys. Res., 100, 26 061-26092, 1995.

Pierce, J. R. and Adams, P. J.: Efficiency of cloud condensation nuclei formation from ultrafine particles, Atmos. Chem. Phys., 7, 1367-1379, 2007, http://www.atmos-chem-phys.net/7/1367/2007/.

Pittock, A., Ackerman, T., Crutzen, P., MacCracken, M., and Shapiro, C.: Environmental Consequences of Nuclear War, Vol. 1: Physical and Atmospheric Effects, Vol. 28 of SCOPE, Wiley,
Chichester, USA, 1986.

Rao, S., Riahi, K., and Kaarle Kupiainen, Z. K.: Long-term scenarios for black and organic carbon emissions, Environ. Sci., 2, 205-216, doi:10.1080/15693430500397228, 2005.

Reddy, M. S., Boucher, O., Bellouin, N., Schulz, M., Balkanski, Y., Dufresne, J.-L., and Pham, M.: Estimates of global multicomponent aerosol optical depth and direct radiative perturbation in the Laboratoire de Météorologie Dynamique general circulation model, J. Geophys. Res., 110, D10S16, doi:10.1029/2004JD004757, 2005.

Rockel, B., Raschke, E., and Weyres, B.: A parameterization of broad band radiative transfer properties of water, ice, and mixed clouds, Contr. Atmos. Phys., 64, 1-12, 1991.

Roeckner, E., Baeuml, G., Bonventura, L., Brokopf, R., Esch, M., Giorgetta, M., Hagemann, S., Kirchner, I., Kornblueh, L., Manzini, E., Rhodin, A., Schlese, U., Schulzweida, U., and Tompkins, A.: The atmospheric general circulation model ECHAM5. PART I: Model description, Report 349, Max Planck Institute for Meteorology, Hamburg, Germany, available from http://www.mpimet.mpg.de, 2003.

Roeckner, E., Stier, P., Feichter, J., Kloster, S., Esch, M., and Fischer-Bruns, I.: Impact of carbonaceous aerosol forcing on regional climate change, Clim. Dynam., 553-571, doi:10.1007/s00382-006-0147-3, 2006.

Schaap, M., Van Der Gon, H. A. C. D., Dentener, F. J., Visschedijk, A. J. H., Van Loon, M., ten Brink, H. M., Putaud, J.-P., Guillaume, B., Liousse, C., and Builtjes, P. J. H.: Anthropogenic black carbon and fine aerosol distribution over Europe, J. Geophys. Res., 109, D18207, doi:10.1029/2003JD004330, 2004.

Schulz, M., de Leeuw, G., and Balkanski, Y.: Emission of atmospheric trace compounds, chap. Sea-salt aerosol source functions and emissions, Ed. Kluwer, 333-359, 2004.

Schulz, M., Textor, C., Kinne, S., Balkanski, Y., Bauer, S., Berntsen, T., Berglen, T., Boucher, O., Dentener, F., Guibert, S., Isaksen, I., Iversen, T., Koch, D., Kirkevåg, A., Liu, X., Montanaro, V., Myhre, G., Penner, J., Pitari, G., Reddy, S., Seland, $\varnothing .$, Stier, P., and Takemura, T.: Radiative forcing by aerosols as derived from the AeroCom present-day and pre-industrial simulations, Atmos. Chem. Phys., 6, 5225-5246, 2006, http://www.atmos-chem-phys.net/6/5225/2006/.

Seinfeld, J. H. and Pandis, S. N.: Atmospheric chemistry and physics: from air pollution to climate change, WileyInterscience, New York, USA, 2nd edn., 2006.

Shettle, E. P. and Fenn, R. W.: Models of the aerosols of the lower atmosphere and the effects of humidity variations on their optical properties, Tech. rep., Air Force Geoph. Lab., Massachusetts, project 7670, 1979.

Simmons, A. J. and Gibson, J. K.: The ERA-40 project plan, ERA40 Project Report Series 1, ECMWF, Shinfield Park, Reading, UK, 2000.

Stier, P., Feichter, J., Kinne, S., Kloster, S., Vignati, E., Wilson, J., Ganzeveld, L., Tegen, I., Werner, M., Schulz, M., Balkanski, Y., Boucher, O., Minikin, A., and Petzold, A.: The aerosolclimate model ECHAM5-HAM, Atmos. Chem. Phys., 5, 11251165,2005 , http://www.atmos-chem-phys.net/5/1125/2005/.

Stier, P., Feichter, J., Kloster, S., Vignati, E., and Wilson, J.: Emission-induced nonlinearities in the global aerosol system Results from the ECHAM5-HAM aerosol-climate model, J. Cli- 
mate, 19, 3845-3862, 2006 .

Stier, P., Feichter, J., Roeckner, E., Kloster, S., and Esch, M.: The evolution of the global aerosol system in a transient climate simulation from 1860 to 2100, Atmos. Chem. Phys., 6, 3059-3076, $2006 b$.

Stier, P., Seinfeld, J. H., Kinne, S., Feichter, J., and Boucher, O.: Impact of nonabsorbing anthropogenic aerosols on clearsky atmospheric absorption, J. Geophys. Res., 111, D18201, doi:10.1029/2006JD007147, 2006c.

Takemura, T., Nozawa, T., Emori, S., Nakajima, T. Y., and Nakajima, T.: Simulation of climate response to aerosol direct and indirect effects with aerosol transport-radiation model, J. Geophys. Res., 110, D02202, doi:10.1029/2004JD005029, 2005.

Tegen, I. and Fung, I.: Contribution to the atmospheric mineral aerosol load from land surface modification, J. Geophys. Res., 100, 18 707-18 726, 1995.

Tegen, I., Harrison, S. P., Kohfeld, K., Prentice, I. C., Coe, M., and Heimann, M.: Impact of vegetation and preferential source areas on global dust aerosol: Results from a model study, J. Geophys. Res., 107, 4576-4597, 2002.

Tegen, I., Werner, M., Harrison, S. P., and Kohfeld, K. E.: Relative importance of climate and land use in determining present and future global soil dust emission, Geophys. Res. Lett., 31, L05105, doi:10.1029/2003GL019216, 2004.

Textor, C., Schulz, M., Guibert, S., Kinne, S., Balkanski, Y., Bauer, S., Berntsen, T., Berglen, T., Boucher, O., Chin, M., Dentener, F., Diehl, T., Easter, R., Feichter, H., Fillmore, D., Ghan, S., Ginoux, P., Gong, S., Grini, A., Hendricks, J., Horrowitz, L., Huang, P., Isaksen, I., Iversen, T., Kirkevåg, A., Kristjansson, J. E., Kloster, S., Koch, D., Kroll, M., Lauer, A., Lamarque, J., Liu, X., Montanaro, V., Myhre, G., Penner, J., Pitari, G., Reddy, S., Seland, Ø., Stier, P., Takemura, T., and Tie, X.: Analysis and quantification of the diversities of aerosol life cycles within AeroCom, Atmos. Chem. Phys., 6, 1777-1813, 2006,

http://www.atmos-chem-phys.net/6/1777/2006/.

Tiedtke, M.: A comprehensive mass flux scheme for cumulus parameterization in large scale models, Mon. Wea. Rev., 117, 1779-1800, 1989.

Tompkins, A.: A prognostic parameterization for the subgrid-scale variability of water vapor and clouds in large-scale models and its use to diagnose cloud cover, J. Atmos. Sci., 59, 1917-1942, 2002.

Toon, O. B. and Ackerman, T. P.: Algorithms for the calculation of scattering by stratified spheres, Appl. Opt., 20, 3657-3660, 1981.

Toon, O. B., Pollack, J. B., and Khare, B. N.: The optical constants of several atmospheric aerosol species: Ammonium sulfate, ammonium oxide and sodium chloride, J. Geophys. Res., 81, 57335748, 1976.

Turco, R., Toon, O., Ackerman, T., Pollack, J., and Sagan, C.: Climate and smoke: an appraisal of nuclear winter, Science, 247, 166-176, doi:10.1126/science.11538069, 1990.

Twomey, S.: Pollution and the planetary albedo, Atmos. Environ., 8, 1251-1256, 1974.

Twomey, S.: The influence of pollution on the shortwave albedo of clouds, J. Atmos. Sci., 34, 1149-1152, 1977.

van der Werf, G. R., Randerson, J. T., Collatz, G. J., and Giglio, L.: Carbon emissions from fires in tropical and subtropical ecosystems, Global Change Biol., 9, 547-562, 2003.

van Poppel, L. H., Friedrich, H., Spinsby, J., Seinfeld, S. H. C. J. H., and Buseck, P. R.: Electron tomography of nanoparticle clusters: Implications for atmospheric lifetimes and radiative forcing of soot, Geophys. Res. Lett., 32, L24811, doi:10.1029/2005GL024461, 2005.

Vignati, E., Wilson, J., and Stier, P.: M7: a size resolved aerosol mixture module for the use in global aerosol models, J. Geophys. Res., 109, D22202, doi:10.1029/2003JD004485, 2004.

Yu, H., Kaufman, Y. J., Chin, M., Feingold, G., Remer, L. A., Anderson, T. L., Balkanski, Y., Bellouin, N., Boucher, O., Christopher, S., DeCola, P., Kahn, R., Koch, D., Loeb, N., Reddy, M. S., Schulz, M., Takemura, T., and Zhou, M.: A review of measurement-based assessments of the aerosol direct radiative effect and forcing, Atmos. Chem. Phys., 6, 613-666, 2006, http://www.atmos-chem-phys.net/6/613/2006/.

Zhang, J. and Christopher, S. A.: Longwave radiative forcing of Saharan dust aerosols estimated from MODIS, MISR, and CERES observations on Terra, Geophys. Res. Lett., 30, 2188, doi:10.1029/2003GL018479, 2003. 